\title{
The Molecular Gatekeeper Dexras1 Sculpts the Photic Responsiveness of the Mammalian Circadian Clock
}

\author{
Hai-Ying M. Cheng, ${ }^{1}$ Heather Dziema, ${ }^{1}$ Joseph Papp, ${ }^{1}$ Daniel P. Mathur, ${ }^{1}$ Margaret Koletar, ${ }^{2}$ Martin R. Ralph, ${ }^{2}$ \\ Josef M. Penninger, ${ }^{3}$ and Karl Obrietan ${ }^{1}$ \\ ${ }^{1}$ Department of Neuroscience, The Ohio State University, Columbus, Ohio 43210, ${ }^{2}$ Centre for Biological Timing and Cognition and Department of \\ Psychology, University of Toronto, Toronto, Ontario, Canada M5S 3G3, and ${ }^{3}$ Institute of Molecular Biotechnology of the Austrian Academy of Sciences, \\ A-1030 Vienna, Austria
}

The mammalian master clock, located in the suprachiasmatic nucleus (SCN), is exquisitely sensitive to photic timing cues, but the key molecular events that sculpt both the phasing and magnitude of responsiveness are not understood. Here, we show that the Ras-like G-protein Dexras1 is a critical factor in these processes. Dexras1-deficient mice (dexras $\left.1^{-/-}\right)$exhibit a restructured nighttime phase response curve and a loss of gating to photic resetting during the day. Dexras 1 affects the photic sensitivity by repressing or activating time-of-day-specific signaling pathways that regulate extracellular signal-regulated kinase (ERK)/mitogen-activated protein kinase (MAPK). During the late night, Dexras 1 limits the capacity of pituitary adenylate cyclase (PAC) activating peptide (PACAP)/PAC1 to affect ERK/MAPK, and in the early night, light-induced phase delays, which are mediated predominantly by NMDA receptors, are reduced as reported previously. Daytime photic phase advances are mediated by a novel signaling pathway that does not affect the SCN core but rather stimulates ERK/MAPK in the SCN shell and triggers downregulation of clock protein expression.

Key words: Dexras1; MAPK; circadian; photic; entrainment; PACAP; suprachiasmatic

\section{Introduction}

Diverse life forms have evolved circadian timing mechanisms ensuring that biological processes are regulated at near $24 \mathrm{~h}$ cycles (Dunlap, 1999). The mammalian master pacemaker is located in the suprachiasmatic nucleus (SCN) (Ralph et al., 1990). The SCN receives external timing cues and provides signals that synchronize oscillations in brain and peripheral tissues. Timing cues (e.g., light) reset and entrain the SCN clock, ensuring that circadian rhythms of behavior and physiology maintain an appropriate temporal relationship with respect to each other and the environment.

A hallmark of circadian timing is that the clock responds to resetting signals in a phase-restricted manner. In nocturnal rodents, light is an effective entrainment cue at dusk and dawn but not during the midday (Decoursey, 1964; Pittendrigh and Daan, 1976). Conversely, behavioral arousal, a nonphotic stimulus, phase-shifts the clock only during the day (Bobrzynska and Mrosovsky, 1998). Temporal responses of the clock to entraining inputs are represented as a phase response curve (PRC) (Daan and Pittendrigh, 1976). The shape and amplitude of a PRC are established by the state of the molecular clock and the signal-

Received June 4, 2006; revised 0ct. 31, 2006; accepted Nov. 6, 2006.

This work was supported by National Institutes of Health Grants MH62335 and NS47176 (K.O.). H.-Y.M.C. was supported by a postdoctoral fellowship from the Canadian Institute of Health Research. We thank Dr. Paul Albert for the generous gift of the $\beta$ ARK-ct expression construct. We are grateful to Phillip Horne, Greg Butcher, Yunsik Choi, Boyoung Lee, and Akshata Almad for technical assistance and helpful discussion.

Correspondence should be addressed to Hai-Ying M. Cheng, Department of Neuroscience, The Ohio State University, Graves Hall, Room 4118, 333 West 10th Avenue, Columbus, OH 43210. E-mail: hymcheng@yahoo.ca.

DOI:10.1523/JNEUROSCI.4253-06.2006

Copyright $\odot 2006$ Society for Neuroscience ～0270-6474/06/2612984-12\$15.00/0 transducing capacity of the input pathways. Phase-restricted responsiveness and clock-controlled gating of clock inputs remain central tenets within the field.

The $\mathrm{p} 42 / \mathrm{p} 44$ mitogen-activated protein kinase (MAPK) pathway has been implicated in circadian entrainment and represents a potential substrate for clock-controlled gating of clock inputs. This pathway is light-inducible in the SCN in a phase-restricted manner (Obrietan et al., 1998), couples light to transcriptional activation (Dziema et al., 2003), and mediates photic phase shifts (Butcher et al., 2002; Coogan and Piggins, 2003). MAPK activation is triggered by glutamate and pituitary adenylate cyclase activating peptide (PACAP), which are cotransmitters of the retinohypothalamic tract (RHT) and convey photic information to the SCN (Obrietan et al., 1998; Butcher et al., 2005).

Although it is recognized that the SCN controls its own sensitivity and therefore shapes the PRCs, the key signaling events that impart this sensitivity are unclear. Potentially, rhythmic availability of a key signaling molecule within an input pathway or, alternatively, a modulator of such a pathway confers both phase specificity and sensitivity to the stimulus. One such candidate is Dexras1, a Ras-like G-protein that exhibits clock-dependent rhythms of expression in the SCN (Cismowski et al., 1999; Panda et al., 2002; Ueda et al., 2002; Takahashi et al., 2003).

Biochemically, Dexras1 functions as a guanine nucleotide exchange factor (GEF) for $\mathrm{G}_{\mathrm{i} / \mathrm{o}} \alpha$ subunits (Cismowski et al., 2000). Dexras 1 has been implicated as a receptor-independent activator of $\mathrm{G}_{\mathrm{i} / \mathrm{o}}$-protein signaling (Cismowski et al., 1999) as well as a context-dependent modulator of the MAPK cascade and other signal transduction pathways, including adenylyl cyclases (ACs) 
and NMDA receptor-nitric oxide (NO)-mediated signaling (Fang et al., 2000; Graham et al., 2004; Nguyen and Watts, 2005).

Here, we provide data revealing that Dexras1 plays a critical role in shaping the photic PRC and the signaling events through which it regulates clock entrainment. These findings provide new insight into the complex set of signaling events that underlie clock entrainment and PRC shape.

\section{Materials and Methods}

Generation of Dexras1(A178V) transgenic mice. The point mutation alanine $178 \rightarrow$ valine was introduced into the I.M.A.G.E. clone encoding the cDNA of murine Dexras1 (American Type Culture Collection, Manassas, VA) using the QuikChange Site-Directed Mutagenesis kit (Stratagene, La Jolla, CA). Full-length Dexras1(A178V) was subcloned into the expression vector pIRES2-eGFP (Clontech, Mountain View, CA), and the Dexras1(A178V)-IRES2-eGFP cassette was subsequently moved into the tetracycline-inducible expression vector pTRE-TIGHT (Clontech). Using the construct TRE-TIGHT-Dexras1(A178V)-IRES-eGFP, three independent transgenic mouse lines were established, which showed similar patterns and levels of enhanced green fluorescent protein (eGFP) expression in founder screens. Data are presented from double transgenic mice generated from intercrosses between line \#3901 and calcium calmodulin-dependent kinase II $\alpha$ (CaMKII $\alpha)$-tetracycline transactivator (tTA) mice (Mayford et al., 1996). Experiments were performed on 8- to 16-week-old mice that had been maintained under standard, doxycycline-free conditions at the animal facility of The Ohio State University, in accordance with institutional guidelines.

Behavioral analyses. Mice were singly housed in cages equipped with a running wheel in light-tight, ventilated boxes with controlled lighting. Wheel-running activity was monitored and analyzed with VitalView and Actiview (MiniMitter, Sunriver, OR). Mice were entrained to a $12 \mathrm{~h}$ light/dark (LD) cycle (400 lux) for at least 1 week before any experimental manipulation. For the photic phase response curve, mice received a 15 min light pulse of 40 lux (at one of the following Zeitgeber (ZT) times: 14, 17,20 , or 23 ) and subsequently released into constant darkness (DD) for 7-10 d. For light pulses administered at ZT 2, 5, 8, and 11, on the day of the experiment, mice were put into DD at ZT 0 and received a $15 \mathrm{~min}$ light pulse of 40 lux at the appropriate ZT time. The animals remained in $\mathrm{DD}$ for at least 1 week after the pulse. For all other behavioral experiments, mice were entrained to a $12 \mathrm{~h} \mathrm{LD}$ cycle (400 lux) and received a 15 min light pulse at a given light intensity (40 or 400 lux) exactly as described above or after 8-12 d in DD. Mice were maintained at the animal facility of The Ohio State University in accordance with institutional guidelines. All animal handling and experimental procedures were approved by the Animal Welfare Committee of The Ohio State University.

Cannulation and infusion. Mice were cannulated in the third or lateral ventricle as described previously (Butcher et al., 2002) and allowed to recover for a minimum of $10 \mathrm{~d}$ after cannulation. For the infusion, mice were restrained by hand under red light, and the infusate was delivered at a rate of $0.4 \mu \mathrm{l} / \mathrm{min}$. Full-length PACAP was diluted in physiological saline to a final concentration of $40 \mu \mathrm{M}$ and injected at a volume of $3 \mu \mathrm{l}$. PACAP 6-38 (500 $\mu \mathrm{M}$ in physiological saline) was injected at a volume of $3 \mu \mathrm{l}, 30 \mathrm{~min}$ before photic stimulation or PACAP infusion. 1,4-Diamino2,3-dicyano-1,4-bis[2-amino-phenylthio]butadiene (U0126) was diluted to $10 \mathrm{~mm}$ in DMSO, and $3 \mu \mathrm{l}$ was injected $30 \mathrm{~min}$ before light treatment. Control animals were infused with an equivalent volume of vehicle (saline or DMSO). We have consistently used a $3 \mu$ l volume for lateral and third ventricle infusions (Butcher et al., 2002, 2005; Dziema et al., 2003) and have not detected any long-term effects on SCN-regulated physiology, signaling, or behavior. Likewise, SCN morphology is not affected. Thus, we are confident that the volume used and the slow rate of infusion do not cause complicating side effects. In addition, it should be noted that the volume change resulting from the infusion $(+3 \mu \mathrm{l})$ is partially offset by the loss of CSF (typically several microliters) that occurs after withdrawal of the cannula plug.

Cell culture and transfection. Embryonic rat cortical neuronal cultures were prepared from embryonic day 19-20 Sprague Dawley rat pups exactly as described previously (Lee et al., 2005). After 8-10 d in vitro, the primary cortical neuron cultures were transfected in a 24-well plate format ( $1 \mu \mathrm{g}$ of DNA per well) using Lipofectamine 2000 (Invitrogen, Carlsbad, CA) according to the instructions of the manufacturer. The following constructs were used: pcDNA3.1+Hygro, pCMV-SPORT6Dexras1(wt), $\beta$ ARK-ct, pGL3-CRE-luciferase, E1B-luciferase, and Gal4Elk1. Cells were treated $36 \mathrm{~h}$ posttransfection with the appropriate stimuli, and cell lysates were prepared $6 \mathrm{~h}$ after stimulation. Luciferase activity was measured using the Bright-Glo Luciferase Assay System (Promega, Madison, WI). To assess PACAP-mediated extracellular signal-regulated kinase (ERK) activation in culture, cortical neurons were treated as follows: tissue culture media were replaced with HEPES buffer (in mM: $137 \mathrm{NaCl}, 25$ glucose, $10 \mathrm{HEPES}, 5 \mathrm{KCl}, 1 \mathrm{MgCl}_{2}$, and 3 $\mathrm{CaCl}_{2}, \mathrm{pH}$ 7.4) containing tetrodotoxin $(1 \mu \mathrm{M}) 30 \mathrm{~min}$ before experimental manipulation. Cells were pretreated (30 min) with PACAP 6-38 (200 nM) before a 15 min stimulation with PACAP (50 nM) and fixed (15 min) with paraformaldehyde ( $4 \% \mathrm{w} / \mathrm{v})$. Phospho-ERK1/2 immunofluorescent labeling was performed as described previously (Butcher et al., 2005) using polyclonal antibodies against phospho-p44/42 MAP kinase (Thr202/Tyr204) (1:3000 dilution; Cell Signaling Technology, Beverly, MA). To identify neurons, cells were also labeled with a neuronal-specific nuclear protein $(\mathrm{NeuN})$ monoclonal antibody (1:1000; Chemicon, Temecula, CA). Cells were processed with Alexa Fluor 488-conjugated goat anti-rabbit IgG antibody (1:1000; Invitrogen) and Alexa Fluor 594conjugated goat anti-mouse IgG antibody (1:1000; Invitrogen), and digital images were captured using a Zeiss (Oberkochen, Germany) 510 Meta confocal microscope.

Tissue collection and immunohistochemistry. Mice were maintained on a fixed $12 \mathrm{~h} \mathrm{LD}$ schedule for a minimum of 2 weeks and dark adapted for $2 \mathrm{~d}$ before treatment. Unless otherwise stated, a single light pulse (15 min; 40 lux) was administered at circadian time (CT) 6 or CT 20, and the mice were returned to darkness before they were killed. p-ERK, c-Fos, and Per2 protein levels were assessed $30 \mathrm{~min}, 2 \mathrm{~h}$, and $6 \mathrm{~h}$ after the start of the light pulse, respectively. For CT 6 light-induced p-ERK determination, a 5 min light pulse was administered. Control animals not exposed to light were killed at the same circadian time. Tissue processing, immunohistochemistry, and image analysis were performed exactly as described previously (Butcher et al., 2002). The following antibodies were used: phospho-p44/42 MAP kinase (Thr202/Tyr204) (1:3000 dilution; Cell Signaling Technology), c-Fos (1:40,000 dilution; Calbiochem, La Jolla, CA), Per2 (1:2500 dilution; Alpha Diagnostic International, San Antonio, TX), and biotinylated anti-rabbit IgG antibody (1:300; Vector Laboratories, Burlingame, CA). Immunodetection was accomplished using the horseradish peroxidase (HRP)-ABC technique (Vector Laboratories) according to the instructions of the manufacturer. Nickelintensified diaminobenzidine was used to visualize the signal. To quantify pERK expression, images of coronal hypothalamus were captured with a $10 \times$ objective and recorded using MetaMorph software (Universal Imaging, West Chester, PA). For analysis of pERK expression at CT 20 , a digital oval 150 pixels $(x$-axis) $\times 200$ pixels ( $y$-axis) was placed within the ventral SCN, and the mean pixel intensity was recorded. For analysis of pERK expression at CT 6, a crescent 150-pixel ( $x$-axis)-wide was placed over the SCN shell, and the mean pixel intensity was recorded. Signal intensity for each SCN was normalized by subtracting the mean level recorded within a 200-pixel-wide circle placed within the hypothalamus lateral to the SCN. pERK data for each animal (two to three central SCN sections) were averaged, and then mean values were averaged for each time point. Absolute intensity measurements for pERK are expressed using a $0-4096$ intensity scale.

Tissue used for fluorescent labeling was processed exactly as described previously (Butcher et al., 2005). The following primary antibodies were used: rabbit polyclonal anti-GFP (1:2000; University of Alberta, Edmonton, Alberta, Canada), and mouse monoclonal anti-phosphorylated ERK (1:2000; Sigma, St. Louis, MO). The following day, the sections were incubated with Alexa Fluor 488-conjugated goat anti-rabbit IgG antibody (1:1000; Invitrogen) and Alexa Fluor 594-conjugated goat anti-mouse IgG antibody (1:1000; Invitrogen). Fluorescent images were captured using a Zeiss 510 Meta confocal microscope (1- $\mu$ m-thick optical section).

Western blotting. SCN tissues were dissected and stored at $-80^{\circ} \mathrm{C}$ until use. SCN tissues from four same-treated mice were pooled. Preparation 
of protein lysate, PAGE, electroblotting, and immunodetection were performed as described previously (Lee et al., 2005). The following antibodies were used: affinity-purified rabbit polyclonal anti-cAMP response element (CRE)-binding protein (CREB) phosphorylated at $\operatorname{Ser}^{133}$ (1: 1000 dilution; Cell Signaling Technology); rabbit polyclonal antiERK1/2 (1:2000 dilution; Santa Cruz Biotechnology, Santa Cruz, CA); goat anti-rabbit IgG antibody conjugated to HRP (1:2000 dilution; PerkinElmer, Norwalk, CT); and goat anti-rabbit IgG antibody conjugated to alkaline phosphatase (AP) (1:2000 dilution; PerkinElmer). Bands were visualized using Renaissance chemiluminescent HRP or AP substrate (PerkinElmer).

cAMP assay. Mice were entrained to a fixed $12 \mathrm{~h} \mathrm{LD}$ schedule for a minimum of 2 weeks and dark adapted for $2 \mathrm{~d}$ before treatment. At CT 20 , mice received a $5 \mathrm{~min}$ light pulse of 40 lux and were decapitated immediately. The SCN was dissected, frozen on dry ice, and stored at $-80^{\circ} \mathrm{C}$ until additional processing. Tissue from individual subjects was homogenized in $200 \mu \mathrm{l}$ of $0.1 \mathrm{~N} \mathrm{HCl}$, and lysates were centrifuged for 2 $\mathrm{min}$ at 13,000 rpm. For each sample, a $100 \mu \mathrm{l}$ aliquot of a 1:5 dilution was assayed using a direct method ELISA (Assay Designs, Ann Arbor, MI) according to the instructions of the manufacturer.

\section{Results}

\section{The absence of Dexras 1 restructures photic sensitivity as a} function of the circadian phase

Given that Dexras1 is rhythmically expressed in the SCN (Panda et al., 2002; Ueda et al., 2002; Takahashi et al., 2003), and that clock entrainment is driven by phase-regulated signaling pathways, Dexras 1 may be uniquely positioned to differentially contribute to photic entrainment as a function of circadian time. To begin to address this issue, we constructed a photic PRC of wildtype and dexras $1^{-/-}$mice. The PRC was constructed using light pulses (15 min; 40 lux) at $3 \mathrm{~h}$ intervals throughout the circadian cycle. As previously reported, a light pulse administered in the early subjective night (ZT 14) produced significant phase delays in wild-type but not in dexras $1^{-1-}$ mice (Fig. 1). In contrast, light presented in the late subjective night (ZT 20) induced robust phase advances in dexras $1^{-/-}$mice but not in wild-type controls (Fig. 1), indicating that Dexras1 produces opposite effects on the phase-delaying and phase-advancing effects of light. Also surprising was that the absence of Dexras1 revealed a phase-advancing response to photic stimulation in the middle of the daytime (ZT 8) (Fig. 1). This is in marked contrast to wild-type mice (and most organisms) which, as expected, were not responsive to a light pulse administered in the mid-subjective day (ZT 8) (Fig. 1). The aggregate data indicate that Dexras1 plays a central role in regulating the phasic responsiveness of the clock to light.

\section{The PAC1 receptor and the MAPK cascade couple light to clock entrainment during the late night in dexras $1^{-1-}$ mice} Next, we identified the cellular signaling events that couple photic signals to phase advances during the late night in dexras $1^{-1-}$ mice. A number of studies have shown that glutamate and PACAP are the principal neurotransmitters that convey photic information from the retina to the SCN (Ding et al., 1994; Chen et al., 1999; Kawaguchi et al., 2003). Interestingly, the role of PACAP as an effector of photic entrainment appears to be phasebiased: genetic ablation of PACAP or PAC1 receptors in mice strongly attenuates light-induced phase advances in the late night but has only a modest effect on phase delays in the early night (Hannibal et al., 2001; Kawaguchi et al., 2003). Given the role of PACAP in light-induced phase advances, combined with the finding that dexras1 $1^{-/-}$mice have potentiated light-induced phase advances raised the possibility that Dexras1 regulates PACAP-induced clock entrainment. To address this issue, we infused the PAC1 receptor-selective inhibitor PACAP 6-38 into

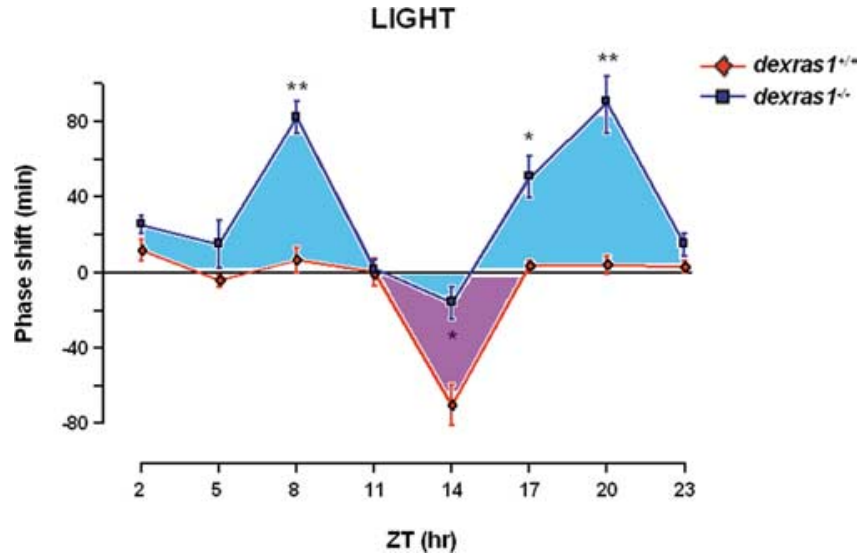

Figure 1. The photic response curve is altered in the absence of Dexras1. dexras $1^{+/+}(\bullet)$ and dexras $1^{-1-}(\mathbf{\square})$ mice were entrained to a fixed $12 \mathrm{~h} \mathrm{LD}$ cycle of 400 lux. On their final LD cycle, the mice received a 15 min light pulse of 40 lux at designated ZT times (ZT 2, 5, 8, 11, 14, $17,20,23)$ and subsequently maintained in DD for at least $7 \mathrm{~d}$. For $Z T 2,5,8$, and 11 experiments, lights remained off at ZT 0 on the day of the light pulse. Values are presented as mean \pm SEM phase shift (in minutes). Positive values on the $y$-axis denote phase advances, whereas negative values denote phase delays. $n=6$ per group. ${ }^{*} p<0.05,{ }^{* *} p<0.01$ versus wild type (twotailed Student's $t$ test).

the third ventricle of dexras $1^{-/-}$mice and assessed phase shifting in response to a single light pulse (15 min; $40 \mathrm{lux}$ ) administered at ZT 20 . Vehicle-infused dexras $1^{-/}$mice showed significant lightinduced phase advances ( $72 \pm 15 \mathrm{~min} ; n=12$ ) (Fig. $2 A$ ). Importantly, infusion of PACAP 6-38 blocked light-induced phase advances in dexras $1^{-1-}$ mice $(8.5 \pm 22 \mathrm{~min} ; n=13$; $p<0.05$ vs vehicle-infused control; two-tailed Student's $t$ test) (Fig. 2A). These data reveal that Dexras1 antagonizes a late-night phaseadvancing signaling pathway initiated by PACAP.

PACAP has been reported to stimulate activation of the MAPK signaling cascade (Barrie et al., 1997; Dziema and Obrietan, 2002; Butcher et al., 2005). Furthermore, in different experimental paradigms, Dexras1 has been shown either to promote or to inhibit MAPK activation (Cismowski et al., 1999; Graham et al., 2002). Given the central role of the MAPK pathway in the phase-delaying effects of light in mice (Butcher et al., 2002), we examined whether MAPK signaling was essential for the phaseadvancing effects of light during the late night in dexras $1^{-/-}$ mice. To this end, dexras1 $1^{-/-}$mice were infused with the MAP kinase kinase 1/2 (MEK1/2) inhibitor U0126, and the phaseshifting effect of a single ZT 20 light pulse (15 min; 40 lux) was examined. Significant light-induced phase advances were observed in vehicle (DMSO)-infused dexras $1^{-1-}$ mice $(72 \pm 7.1$ $\min ; n=6$ ) (Fig. $2 B$ ) but not in U0126-treated dexras $1^{-/-}$mice $(-12 \pm 14$ min; $n=6 ; p<0.001$ vs vehicle-infused control; two-tailed Student's $t$ test) (Fig. $2 C$ ). Together, these data indicate that the ability of a signaling cassette formed by PACAP/ PAC1 and MAPK to convey photic timing cues to the clock is regulated by Dexras1.

\section{Dexras1 represses late-night light-induced MAPK signaling in the SCN}

The observation that late-night MAPK-dependent phase advancing is potentiated in dexras $1^{-1-}$ mice (Fig. $3 B$ ) compared with wild-type animals (Fig. $3 A$ ), combined with the recognized role of Dexras1 as a complex, context-specific regulator of the MAPK cascade (Cismowski et al., 1999; Graham et al., 2002), led us to examine the effects of Dexras1 on light-induced MAPK activation. In both wild-type and dexras $1^{-1-}$ mice, a single light pulse 


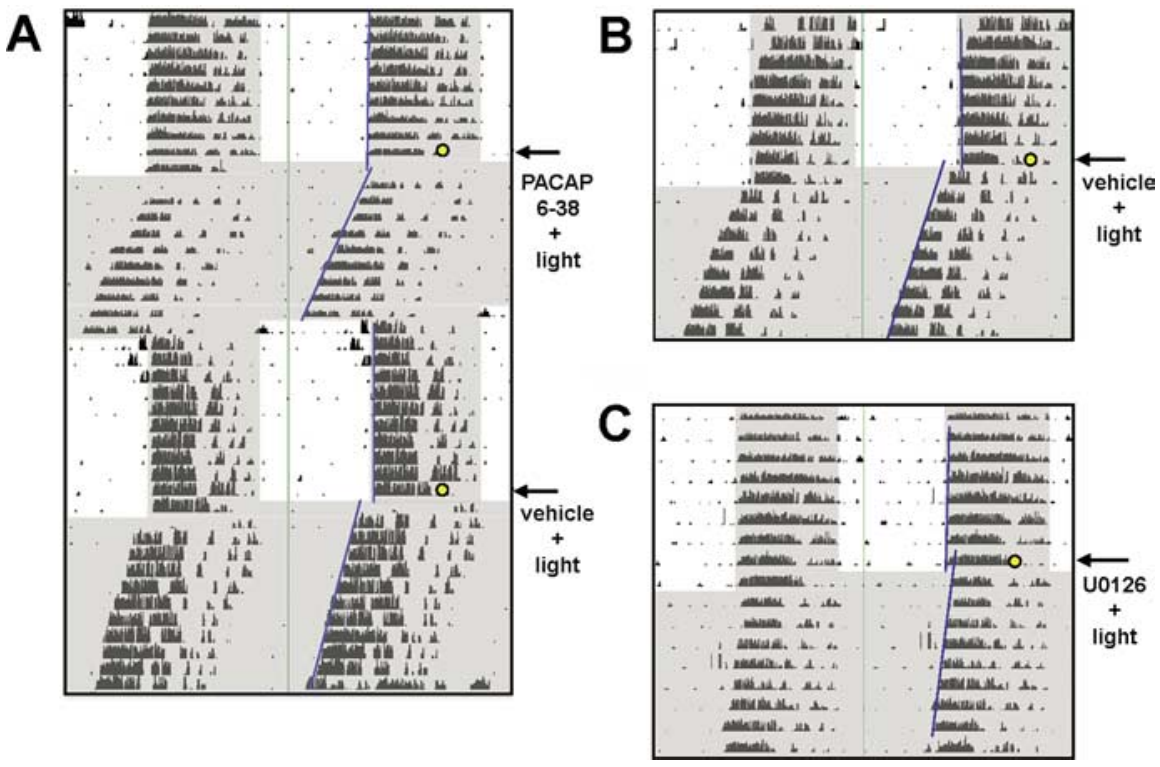

Figure 2. The enhanced late-night photic responsiveness of dexras $1^{-1-}$ mice is dependent on PAC1 receptor and p42/p44 MAPK activity. $\boldsymbol{A}$, A representative actogram of wheel-running activity of dexras $1^{-/}$mice. Mice were entrained to a $12 \mathrm{~h} L D$ schedule (400 lux). Thirty minutes before a $15 \mathrm{~min}$ light pulse of 40 lux at ZT 20 (yellow circle), mice were infused with the PAC1 antagonist PACAP 6-38 (500 $\mu \mathrm{m} ; 3 \mu \mathrm{l}$ ) via a guide cannula positioned in the third ventricle. Subsequent to the light pulse, animals were maintained in DD for at least $7 \mathrm{~d}$. Animals were re-entrained, and the procedure was repeated for the counterbalanced treatment: vehicle infusion plus light pulse. Periods of darkness are shaded in gray. Activity onsets are indicated by blue lines. $\boldsymbol{B}, \boldsymbol{C}$, Representative actograms of wheel-running activity of dexras $1^{-/-}$mice. Mice were entrained to a $12 \mathrm{~h} L D$ schedule (400 lux). Thirty minutes before a $15 \mathrm{~min}$ light pulse of 40 lux at ZT 20 (yellow circle), mice were infused with vehicle (DMSO) (B) or the MEK1/2 inhibitor U0126 (10 mm; $3 \mu \mathrm{l})$ (C) via a guide cannula located in the third ventricle. Subsequent to the light pulse, animals were maintained in DD for at least $7 \mathrm{~d}$.

(15 min; 40 lux) administered at CT 20 induced p-ERK expression in the SCN (Fig. 3C). However, the levels of light-induced p-ERK were significantly greater in the SCN of dexras $1^{-1-}$ mice compared with those of wild-type controls. In addition, p-ERK immunoreactivity was observed throughout the SCN in dexras $1^{-1-}$ mice, whereas in wild-type mice, p-ERK expression was confined to the ventral, retinoreceptive region of the SCN (Fig. 3C,F). The augmentation of light-induced p-ERK was paralleled by a greater increase in c-Fos-immunoreactive nuclei in the SCN of dexras1 ${ }^{-1-}$ mice compared with that of wild types (Fig. 3D, G). Interestingly, under basal conditions, there was a significantly greater number of c-Fos-positive nuclei in dexras $1^{-1-}$ SCN compared with wild-type controls (Fig. 3D, G). As reported previously (Yan and Silver, 2002), light exposure in the late night did not induce Per2 expression in the SCN of wild-type mice (Fig. 3E). Consistent with the results from wild-type mice, light did not stimulate Per2 expression in dexras $1^{-1-}$ mice (Fig. 3E). The cumulative evidence indicates that Dexras1 suppresses photic responsiveness of the circadian system in the late night via a negative modulatory effect on light-induced MAPK activation.

\section{Dexras1 negatively regulates PACAP-induced MAPK activation via both limbs of $\mathrm{G}$-protein signaling}

PAC1 receptors belong to the superfamily of G-protein-coupled receptors (GPCRs) that activate multiple intracellular signaling cascades (Spengler et al., 1993). The binding of PACAP to PAC1 induces the GTP-dependent dissociation of $\mathrm{G}_{\mathrm{s}} \alpha$ and $\mathrm{G} \beta \gamma$ subunits, which independently engage multiple downstream effectors, including MAPK and AC (Spengler et al., 1993; Barrie et al., 1997). Given the finding that Dexras1 acts as a guanine nucleotide exchange factor for $\mathrm{G}_{\mathrm{i} / \mathrm{o}} \alpha$ subunits and regulates $\mathrm{G} \beta \gamma$ signaling, we assessed the potential negative regulatory effect of
Dexras1 on PACAP-mediated MAPK activation. To this end, PACAP-mediated activation of the MAPK pathway was monitored in cortical neuron cultures using a GAL4-Elk1/E1B-driven luciferase reporter assay (Chung and Brautigan, 1999). Cotransfection of a Dexras1 expression vector attenuated PACAP-induced Elk1 transactivation relative to pcDNAtransfected controls by 55\% (Fig. 4A). Interestingly, abrogation of $\mathrm{G} \beta \gamma$ activity via cotransfection of a $\mathrm{G} \beta \gamma$ scavenger, the $\mathrm{C}$ terminus of $\beta$-adrenergic receptor kinase ( $\beta$ ARK-ct), reduced PACAP-induced Elk1 transactivation in pcDNA-transfected but not Dexras1-transfected cultures to $60 \%$ of control values (Fig. 4A). These data, which indicate that overexpression of a $\mathrm{G} \beta \gamma$ scavenger phenocopies the effects of Dexras1, suggest that Dexras1 inhibits $\mathrm{G} \beta \gamma$ activity and thereby decreases PACAP-induced MAPK activation.

The incomplete attenuation of PACAP-induced Elk1 transactivation by $\beta A R K-c t$ indicates that an additional, $\mathrm{G} \beta \gamma$-independent pathway is engaged by PACAP and couples to the MAPK pathway. Along these lines, $\mathrm{G}_{\mathrm{s}}$-coupled receptors have been shown to stimulate the MAPK cascade via a cAMP-dependent mechanism (Norum et al., 2003). Interestingly, as a GEF for $\mathrm{G}_{\mathrm{i} / \mathrm{o}}$-protein subtypes, Dexras1 may be an effective modulator of AC-induced MAPK activation. To begin to examine the modulatory effects of Dexras 1 on $\mathrm{G}_{\mathrm{i} / \mathrm{o}}$ activity and the consequence on PACAP-induced MAPK activation, we treated GAL4-Elk1/E1B-luciferase-expressing cortical cultures with the $\mathrm{G}_{\mathrm{i} / \mathrm{o}}$ inhibitor pertussis toxin $(100 \mathrm{ng} / \mathrm{ml}) 2 \mathrm{~h}$ before stimulation with PACAP $(100 \mathrm{nM})$. Pertussis toxin potentiated PACAP-induced Elk1 transactivation in pcDNA-transfected cultures by twofold (Fig. $4 B$ ). This is consistent with the removal of an inhibitory signal impinging after $A C$ in the face of $G_{s}$ mediated stimulation. Pertussis toxin ADP-ribosylates $\mathrm{G}_{\mathrm{i} / \mathrm{o}} \alpha$ and, thus, inhibits $G_{i / o}$-proteins only in the inactive, heterotrimeric form (Tsai et al., 1984). As noted above, Dexras 1 acts as a guanine nucleotide exchange factor for $\mathrm{G}_{\mathrm{i} / \mathrm{o}} \alpha$ subunits, thereby facilitating dissociation of $\mathrm{G}_{\mathrm{i} / \mathrm{o}} \alpha$ from $\mathrm{G} \beta \gamma$. Thus, Dexras1 overexpression should counter the effects of pertussis toxin if Dexras 1 negatively modulates PACAP-induced MAPK via a $G_{\mathrm{i} / \mathrm{o}} \alpha$-dependent mechanism. Indeed, we found that in neurons overexpressing Dexras1, pertussis toxin had no effect on PACAP-induced Elk1 transactivation (Fig. $4 B$ ). Given the mode of action of pertussis toxin, these data suggest that Dexras1 activates $G_{i / o}$-proteins, which have an inhibitory effect on PACAP-mediated, cAMPdependent, MAPK activation. To test this interpretation, the effects of Dexras1 on forskolin-induced Gal4-Elk1-mediated transcription were examined. Consistent with the effects on PACAP, Dexras 1 attenuated forskolin-mediated activation of the MAPK cascade to $30 \%$ of control values (Fig. $4 C$ ). These data indicate that Dexras1 negatively regulates the capacity of $\mathrm{G}_{\mathrm{s}} / \mathrm{cAMP}$ to stimulate MAPK activation in neurons.

The CRE is found in a number of light-responsive genes and has been suggested to couple light to transcriptionally dependent entrainment of the SCN clock (Obrietan et al., 1999). Given the 
A

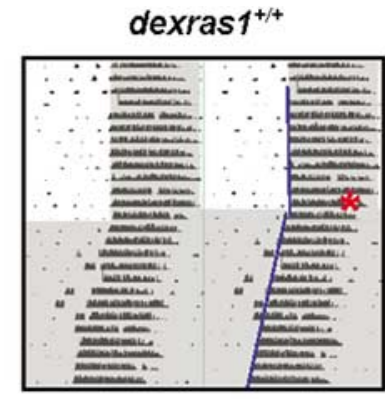

B

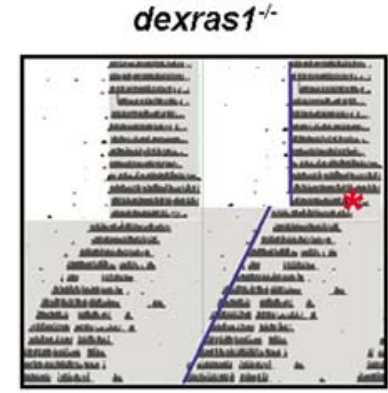

C

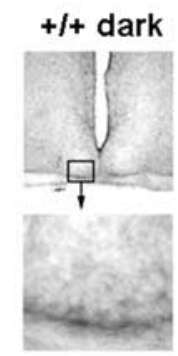

D

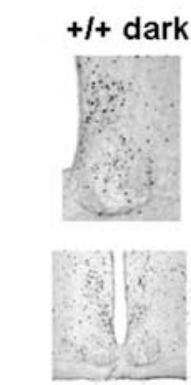

E

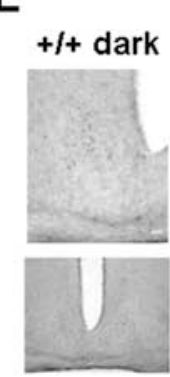

pERK

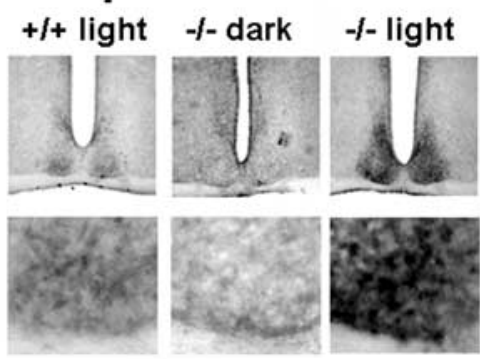

\section{cFos}
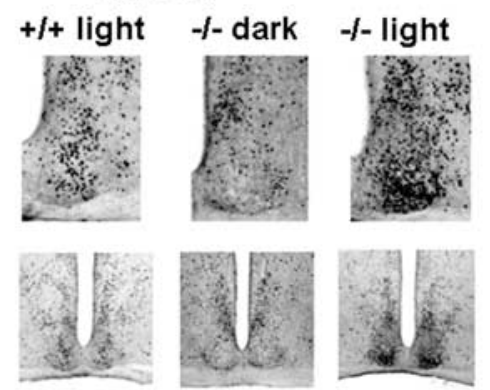

\section{Per2}
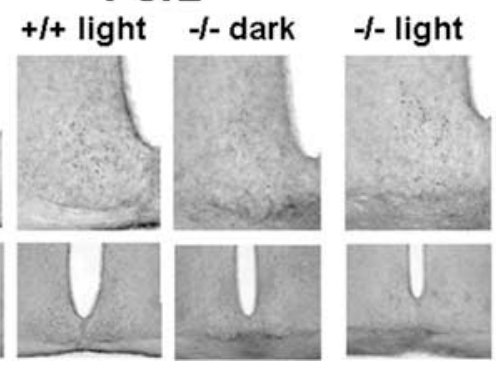

F

no light

$\square$ light

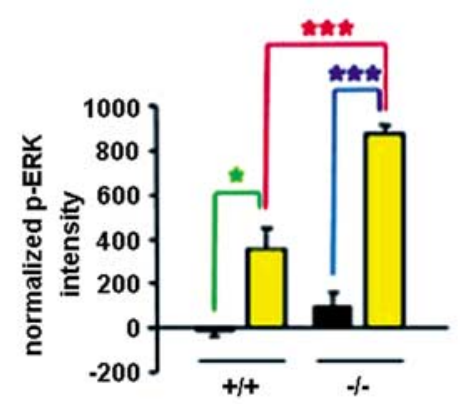

G
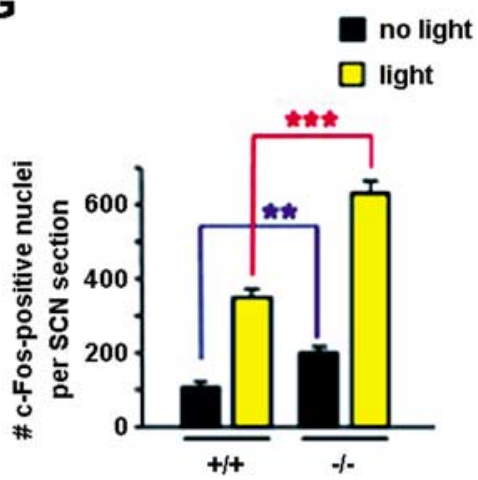

Figure 3. Disruption of Dexras1 potentiates the effects of late-night light exposure. $\boldsymbol{A}, \boldsymbol{B}$, Representative actograms of wheel-running activity of dexras $1^{+/+}(\boldsymbol{A})$ and dexras $1^{-/-}(\boldsymbol{B})$ mice. Mice were exposed to a single 40 lux light pulse for $15 \mathrm{~min}$ at ZT 20 (red asterisk), exactly as described in Figure 1 . Activity onsets are indicated by blue lines. $(-\boldsymbol{E}$, Immunohistochemical analysis of $p$-ERK $(\boldsymbol{C}), \boldsymbol{c}-$ Fos $(\boldsymbol{D})$, and Per2 (E) expression in response to a single $15 \mathrm{~min}$ light pulse at $(T 20$. Wild-type $(+/+)$ and knock-out $(-/-)$ mice were killed $0.5,2$, and $6 \mathrm{~h}$ after the light treatment, and brain sections were processed for phospho-ERK, c-Fos, and Per2, respectively. Dark control animals were not exposed to light but were killed at the same circadian time. $F$, Quantitation of p-ERK expression in the SCN. Data are presented as mean \pm SEM densitometric intensity. Light-induced ERK activation was significantly enhanced in the SCN of dexras $1^{-1-}$ mice relative to wild-type controls. $n=$ 4-6 animals per group. ${ }^{*} p<0.05,{ }^{* * *} p<0.001$ (two-tailed Student's $t$ test). G, Quantitation of c-Fos expression in the SCN. Data are presented as mean \pm SEM c-Fos-immunoreactive nuclei per $\mathrm{SCN}$ section. There was a significantly greater number of c-Fos-immunoreactive nuclei in the $\mathrm{SCN}$ of dexras $7^{-1-}$ versus wild-type mice under basal conditions at $\mathrm{CT} 22$ and $2 \mathrm{~h}$ after light treatment at CT 20. $n=6-7$ per group. ${ }^{* *} p<0.01,{ }^{* * *} p<0.001$ (two-tailed Student's $t$ test).

capacity of Dexras 1 to regulate $\mathrm{G}_{\mathrm{s}}$-mediated signaling, we tested its effects on CRE-mediated gene expression. Neurons were transfected with a CRE-regulated luciferase reporter plasmid and stimulated with forskolin. The coexpression of Dexras 1 attenuated forskolin-induced CRE-mediated transcription by $60 \%$ relative to pcDNA-transfected controls (Fig. 4C). These data suggest that Dexras1 negatively modulates photic responses via an inhibitory effect on CREB/CRE-mediated transcription of clock genes per se or other target genes implicated in photic entrainment.

In a set of control experiments, we stimulated cortical neuronal cultures with PACAP (50 nM) for 15 min and assessed ERK activation. The levels of p-ERK were markedly elevated in PACAP-treated neurons compared with unstimulated cultures (Fig. $4 D$ ). Importantly, a 30 min pretreatment with the PAC1 antagonist PACAP 6-38 (200 nM) significantly suppressed p-ERK expression (Fig. 4D). These data indicate that PACAPdependent signaling events actuated in cortical neurons are likely analogous to those observed in the SCN, although cortical neurons may not perfectly generalize to SCN neurons in terms of precise signaling mechanisms. Our cumulative observations sug- gest that PACAP induces MAPK activation via both the $\mathrm{G}_{\mathrm{s}} \alpha$ and $\mathrm{G} \beta \gamma$ limbs of G-protein signaling, and that Dexras1 not only inhibits $\mathrm{G} \beta \gamma$, but it also provides additional inhibitory influences on $\mathrm{G}_{\mathrm{s}}$ signaling via activation of $\mathrm{G}_{\mathrm{i} / \mathrm{o}}$-proteins.

\section{Dexras1 inhibits cAMP production and cAMP-mediated signaling in the SCN}

The results of the in vitro experiments described above suggested that cAMP-dependent signaling would be upregulated in dexras $1^{-1-}$ mice. To examine this issue, we determined the levels of CAMP in SCN tissues of wild-type and dexras $1^{-/-}$mice during the late night (CT 20) under basal conditions and after light exposure. Basal levels of cAMP were demonstrably greater in dexras $1^{-/-}$SCN relative to wild type (Fig. 5A). Furthermore, a single light pulse at CT 20 evoked a significant increase in cAMP in the SCN of dexras1 $1^{-/-}$but not wild-type mice (Fig. $5 A$ ). In accordance with these data, basal and inducible levels of phospho-CREB were altered in the SCN of dexras $1^{-/-}$mice. In wild-type mice, basal expression of pCREB in the SCN was low at CT 20 (Fig. 5B) and light induced robust pCREB expression. In 
A

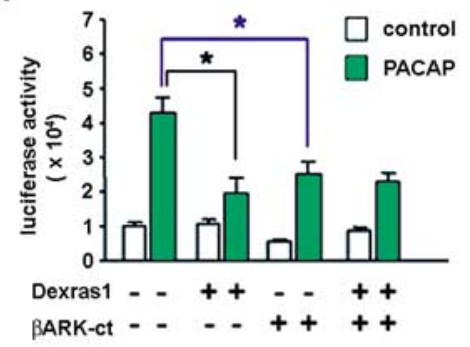

C
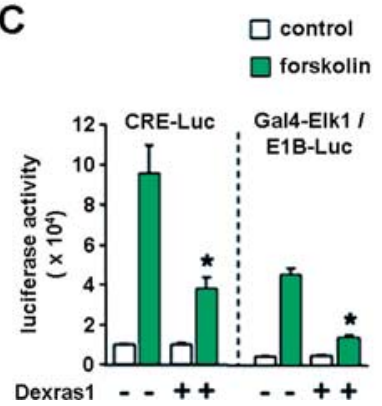

D
B
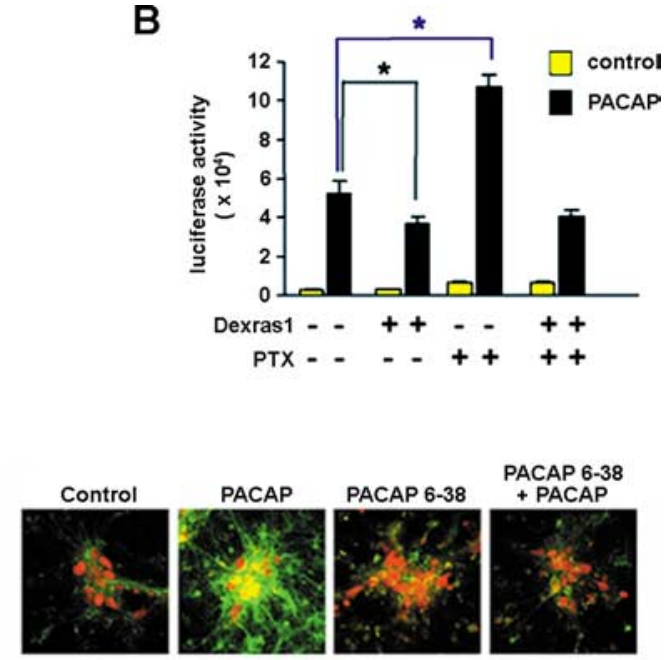

Figure 4. Dexras1 inhibits PACAP-induced $\mathrm{p} 42 / 44$ MAPK activation by a $\mathrm{G} \alpha$ - and $\mathrm{G} \beta \gamma$-dependent mechanism in vitro. $\boldsymbol{A}$, Primary cultures of rat embryonic cortical neurons were maintained for $8 \mathrm{~d}$. Subsequently, they were transfected with an E1Bluciferase reporter gene construct and the Gal4-Elk1 expression vector, in combination with expression constructs for Dexras 1 or a $\mathrm{G} \beta \gamma$ scavenger, $\beta$ ARK-ct. Thirty-six hours posttransfection, cultures were treated with $100 \mathrm{~nm}$ PACAP and assayed $6 \mathrm{~h}$ later. PACAP-induced Gal4-Elk1 activation was attenuated in Dexras1-overexpressing neurons compared with empty vector controls. $\beta A R K-c t$ expression reduced the magnitude of PACAP-induced Gal4-Elk1 activation in empty vector controls only but had no effect on Dexras1-overexpressing neurons. $\boldsymbol{B}$, Cortical neurons were transfected as described in $\boldsymbol{A}$, with or without cotransfection of the Dexras1 expression construct. Cultures received a $2 \mathrm{~h}$ pretreatment with $100 \mathrm{ng} / \mathrm{ml}$ pertussis toxin (PTX) followed by stimulation with $100 \mathrm{~nm}$ PACAP for $6 \mathrm{~h}$. Pertussis toxin potentiated PACAP-induced Gal4-Elk1 activation in empty vector controls but had no effect on Dexras1-overexpressing neurons. C, Cortical neurons were transfected with a CRE-luciferase reporter gene construct or, alternatively, an E1B-luciferase reporter gene construct in combination with the Gal4-Elk1 expression vector. Neurons were cotransfected with empty vector or the Dexras1 expression construct. Thirty-six hours posttransfection, cultures were treated with $10 \mu \mathrm{m}$ forskolin and assayed $6 \mathrm{~h}$ later. In both CRE and E1B assays, the effects of forskolin were significantly reduced by cotransfection of Dexras1. Data are presented as the mean \pm SEM of quadruplicate determinations. ${ }^{*} p<0.05$ versus empty vector control (two-way ANOVA). D, Rat cortical neuronal cultures were stimulated with PACAP ( $50 \mathrm{~nm}$ ) for $15 \mathrm{~min}$ before a $30 \mathrm{~min}$ pretreatment with PACAP 6-38 (200 nm) (far-right panel). After stimulation, cells were fixed and the expression of p-ERK (green), and NeuN (a neuron-specific marker: red) was determined by immunocytochemistry. ERK activation was compared with cultures that had received no treatment (control, far-left panel), PACAP alone (center-left panel), and PACAP 6-38 alone (center-right panel).

dexras $1^{-/-}$mice, not only were basal pCREB levels in the SCN markedly greater compared with wild-type controls, photic stimulation elevated PCREB expression even further, beyond that observed in light-treated wild-type mice (Fig. 5B). Collectively, these data indicate that the effects of Dexras1 on cAMP levels are reflected in the transactivation potential of CREB, one of the central regulators of clock entrainment.

So far, our data indicate that Dexras 1 functions as an inhibitor of signaling events that are initiated by PACAP/PAC1 receptors and impinge after the $\mathrm{p} 42 / \mathrm{p} 44$ MAPK cascade. To test this possibility, we next examined the capacity of PACAP to elicit ERK activation in vivo in wild-type and dexras1 $1^{-/-}$mice. Infusion of PACAP $(40 \mu \mathrm{M} ; 3 \mu \mathrm{l})$ into the lateral ventricle at CT 20 produced a significant increase in p-ERK levels in the SCN and periventricular region of both wild-type and dexras $1^{-/-}$mice (Fig. $5 C, D)$. Quantitative analysis of p-ERK immunoreactivity in the SCN indicated that PACAP was more potent at stimulating ERK activation in the knock-outs compared with the wild types (Fig. 5D). Most notably, pretreatment with PACAP 6-38 (500 $\mu \mathrm{M} ; 3$ $\mu \mathrm{l})$ strongly inhibited the ability of PACAP to elevate p-ERK expression in dexras1 ${ }^{-/-}$mice (Fig. 5C,D). Although these data demonstrate the efficacy of PACAP 6-38 as a potent antagonist of PACAP, we cannot rule out the possibility that PACAP 6-38 might have effects that are not attributed to PACAP. However, in support of its efficacy, PACAP 6-38 has been used in several in vivo studies (Chen et al., 1999; Bergstrom et al., 2003) as a PAC1-selective antagonist and was biochemically characterized in isolated membrane binding studies as a strong competitive antagonist of fulllength PACAP (Robberecht et al., 1992).

In vivo abrogation of light-induced MAPK activation in the SCN of transgenic mice that express a constitutively active form of Dexras 1 To provide in vivo data that Dexras1 expression in the SCN critically modulates the effects of nocturnal light, we generated an inducible transgenic mouse strain that overexpresses a constitutively active form of Dexras1. The alanine $\rightarrow$ valine mutation in codon 178 interrupts the guanine nucleotide binding pocket of Dexras 1 and results in decreased affinity for GTP/GDP binding as well as increased exchange of GDP for GTP (Graham et al., 2001). Transgenic mice were generated, which expressed the A178V mutant form of Dexras1 bicistronically with eGFP under the control of a tetracycline-controlled promoter (Fig. 6A). Individual founder lines were bred with the CaMKII $\alpha$-tTA mice, which drive transgene expression in the absence of doxycycline in a tissuespecific manner. Three of the Dexras1(A178V)-IRES-eGFP founder lines, when intercrossed with CaMKII $\alpha$ tTA, showed transgene expression that was restricted to the SCN (Fig. 6A). The SCN specificity of one of these founder lines, Dexras1(A178V) \#3901, becomes apparent in low-magnification images where the SCNcontaining coronal section can be viewed (Fig. $6 \mathrm{~B}$, left panels). This is in stark contrast to founder lines that exhibit broader expression encompassing the SCN, cortex, striatum, and hippocampus (Fig. $6 \mathrm{~B}$, right panels). All subsequent experiments were performed using the SCN-specific founder lines.

To address the role of Dexras 1 in light-induced MAPK activation in vivo, SCN-specific Dexras1(A178V) double transgenic mice received a brief light pulse in the late subjective night. p-ERK expression was observed in the SCN in response to light but was notably absent in neurons that overexpressed Dexras1(A178V) (Fig. 6C, left panel). The absence of an overlap between the signals for p-ERK and the GFP marker was made more apparent under higher magnification to resolve individual neurons (Fig. 6C, right panel). Hence, using a tissue-specific transgenic approach in a whole animal model, we provide in vivo evidence that Dexras1 functions within the SCN to inhibit the coupling of light to the MAPK pathway.

Dexras1 gates the effects of daytime light exposure on MAPK activation and changes in clock gene expression

In nocturnal rodents, the circadian system is unresponsive to photic cues presented in the day, both at a behavioral as well as a 
cellular level (Pittendrigh and Daan, 1976; Obrietan et al., 1998). However, genetic inactivation of Dexras1 leads to a loss of daytime gating of light (Figs. 1, 7A,B). To examine where within the photic entrainment pathway Dexras1 was affecting the gate, we analyzed the expression of p-ERK, c-Fos, and Per2 after a $15 \mathrm{~min}$ light pulse administered during the subjective daytime. As reported previously (Obrietan et al., 1998), basal levels of p-ERK at CT 6 were strong and confined to the dorsal and mediolateral regions of the SCN of wild-type mice (Fig. 7C), and a single light pulse did not induce additional p-ERK immunoreactivity (Fig. $7 C, F)$. In dexras $1^{-/-}$mice, basal levels of p-ERK were moderately attenuated in the dorsomedial region of the SCN compared with wild-type mice (Fig. 7C,F). Furthermore, light induced a significant increase in p-ERK expression in the dorsomedial SCN (Fig. $7 C, F)$. This region of the SCN encompasses a significant portion of the SCN "shell," the locus of the circadian pacemaker. It is important to note that this light-induced p-ERK expression pattern is distinct from the ventrolateral pattern of p-ERK expression that is normally observed after photic stimulation in the subjective night.

Phase-restricted gene expression was also abrogated in dexras $1^{-/-}$mice. Consistent with light-induced p-ERK expression, we found that photic stimulation during the subjective day (CT 6) triggered a marked increase in expression of the immediate early gene c-Fos (Fig. $7 D, G$ ). Interestingly, under control conditions, dexras $1^{-/}$mice exhibited significantly less c-Fos expression in the dorsomedial SCN than wild-type mice (Fig. $7 D, G)$. Consistent with previous reports (Rusak et al., 1992), light exposure during the day (CT 6) failed to increase the expression of c-Fos in wild-type mice (Fig. $7 D, G$ ).

Paralleling the c-Fos and p-ERK results, dexras $1^{-/-}$mice exhibited marked light-induced PCREB expression at CT 6, whereas in wild-type mice, CREB phosphorylation levels were not affected by light (Fig. 7I).

To assess whether daytime photic responses in dexras $1^{-1-}$ mice correlate with an alteration in the expression of circadian clock proteins, we processed tissue for the expression of Per2. In wild-type mice, a single mid-subjective day (CT 6) light pulse did not alter Per2 expression examined $6 \mathrm{~h}$ later (Fig. $7 E, H$ ). In striking contrast, dexras1 ${ }^{-/-}$mice showed a significant lightinduced reduction in Per2 immunoreactivity in the SCN shell (Fig. $7 E, H)$. Interestingly, this light-induced decrease in Per2 expression mirrors the effects of nonphotic entrainment stimuli presented in the day (Maywood et al., 1999). Together, the data reveal that Dexras1 functions as an essential daytime gate that restricts access of photic information to the shell region of the $\mathrm{SCN}$ but is not necessary for gating of light-induced MAPK activation in the SCN core.

\section{The p42/p44 MAPK cascade is required for daytime photic} phase advances in dexras $1^{-/-}$mice

Nighttime photic entrainment of the circadian clock is driven by the MAPK cascade. To determine whether daytime light responses in dexras1 ${ }^{-1-}$ mice also require signaling via the MAPK pathway, we infused mice with U0126 and examined the behavioral effects of a single light pulse (40 lux; $15 \mathrm{~min}$ ) administered at ZT 8. Vehicle-infused dexras1 ${ }^{-1-}$ mice showed robust lightinduced phase advances ( $76 \pm 11 \mathrm{~min} ; n=6$ ) (Fig. $7 J)$. In contrast, U0126 abrogated the phase-advancing effect of light (4.2 \pm $8.2 \min ; n=6 ; p<0.001$ vs vehicle-infused control; two-tailed Student's $t$ test) (Fig. $7 K$ ). Together, the data indicate that Dexras1 functions as a molecular gate that suppresses MAPKdependent entrainment to light in the day.

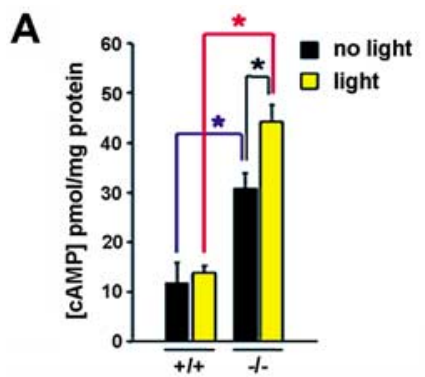

B
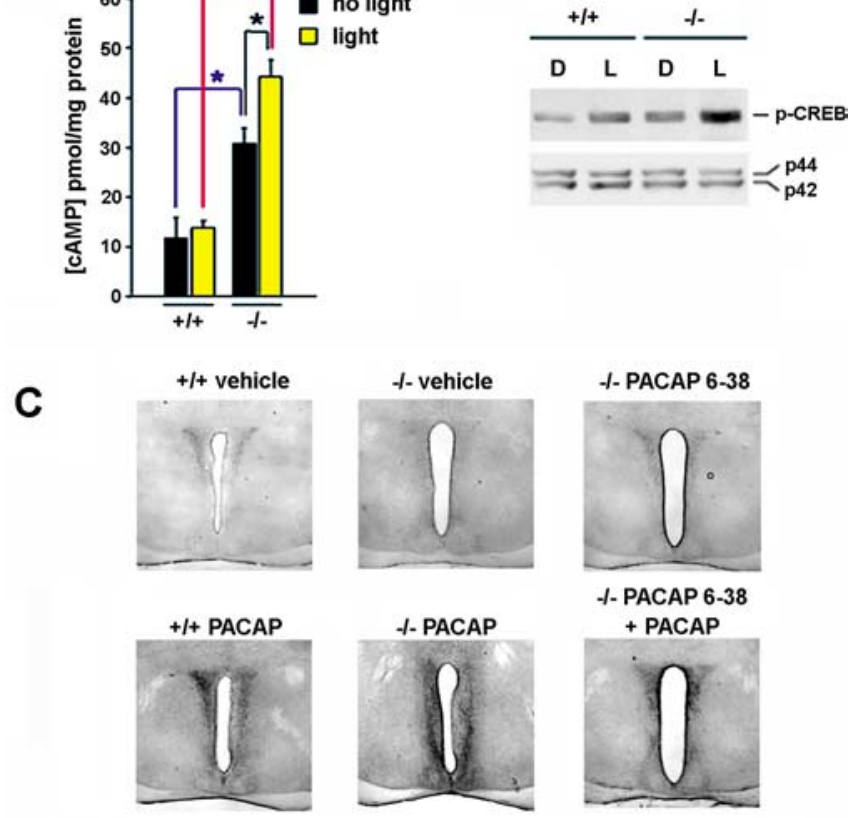

D

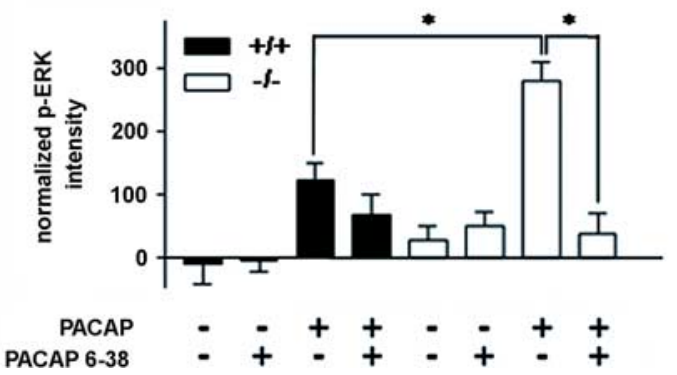

Figure 5. Dexras1 modulates CAMP-dependent signaling and PACAP/PAC1-mediated MAPK activation in the $S C N$. $A$, Wild-type and dexras $1^{-1-}$ mice received a single light pulse $(5 \mathrm{~min}, 40$ lux) at (T 20, and the SCN was dissected immediately and analyzed for CAMP content by ELISA. Control subjects did not receive a light pulse but were killed at the same circadian time. Light did not increase cAMP levels in wild-type mice $(+/+)$. However, dexras $7^{-/-}$mice $(-/-)$exhibited a significant light-induced increase in cAMP. Additionally, under basal conditions, dexras $1^{-1-}$ mice had significantly elevated cAMP levels relative to wild-type mice. Values are presented as mean \pm SEM pmol cAMP per mg of protein. $n=4-5$ per group. ${ }^{*} p<0.05$ (two-way ANOVA). B, Western blot analysis of light-induced p-CREB expression in the SCN. Wild-type and dexras $1^{-/-}$mice received a single light pulse (15 min, 40 lux) at $C T 20$, and the $\mathrm{SCN}$ was dissected $30 \mathrm{~min}$ after the start of the light exposure. Pooled SCN extracts were probed for the expression of $p$-CREB. Expression of total ERK1/2 (p42, p44) was used as the loading control. L denotes light-treated mice, whereas D denotes dark controls. C, D, Wild-type $(+/+)$ and dexras $1^{-1-}(-/-)$ mice were infused with the PAC1 antagonist PACAP $6-38(500 \mu \mathrm{m} ; 3$ $\mu$ l) via a guide cannula positioned in the lateral ventricle $30 \mathrm{~min}$ before a second infusion of PACAP $(40 \mu \mathrm{m} ; 3 \mu \mathrm{l})$. Thirty minutes after the second infusion, mice were killed, and brain sections were processed for $p$-ERK. ERK activation was compared with mice that received infusions of vehicle only, PACAP alone, or PACAP 6-38 alone. Representative micrographs are provided in $\boldsymbol{C}$. Quantitation of p-ERK expression in the $\mathrm{SCN}$ is given in $\boldsymbol{D}$. Data are presented as mean \pm SEM p-ERK-immunoreactive nuclei per $S C N$ section. There was a significant effect of genotype on PACAP-mediated ERK activation as well as a significant effect of PACAP $6-38$ on PACAP-induced $p$-ERK expression in the knock-out SCN. $n=6-7$ per group. ${ }^{*} p<0.01$ (twotailed Student's $t$ test).

\section{SCN-targeted expression of constitutively active Dexras1 leads to aberrant phase-shifting response to late-night light exposure}

Thus far, we have shown that in the absence of Dexras1, late-night phase advances are potentiated and the gated unresponsiveness, which is characteristic of the subjective day, is lost. To provide another line of evidence validating the role of Dexras1 in photic 


\section{A Tet OFF:}
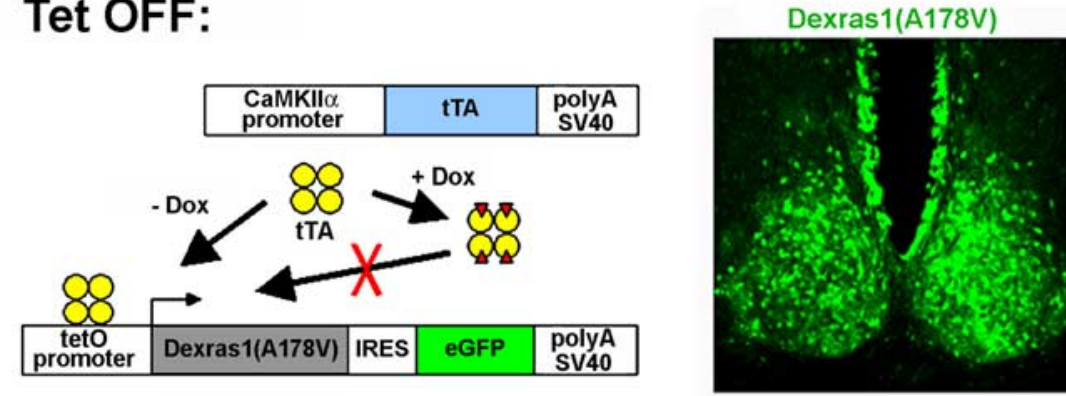

B
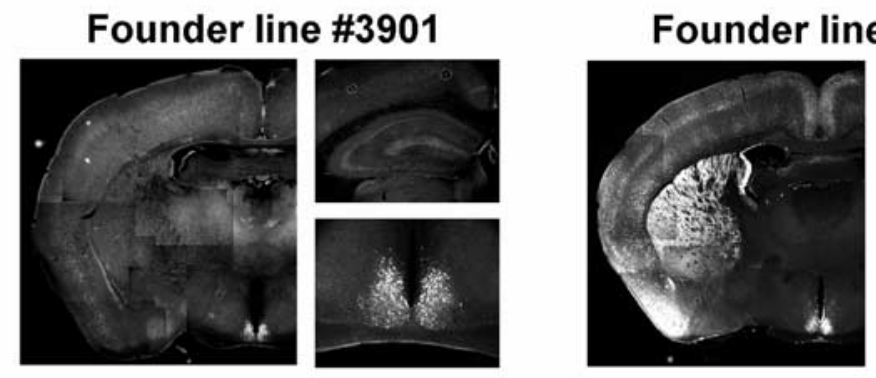

C
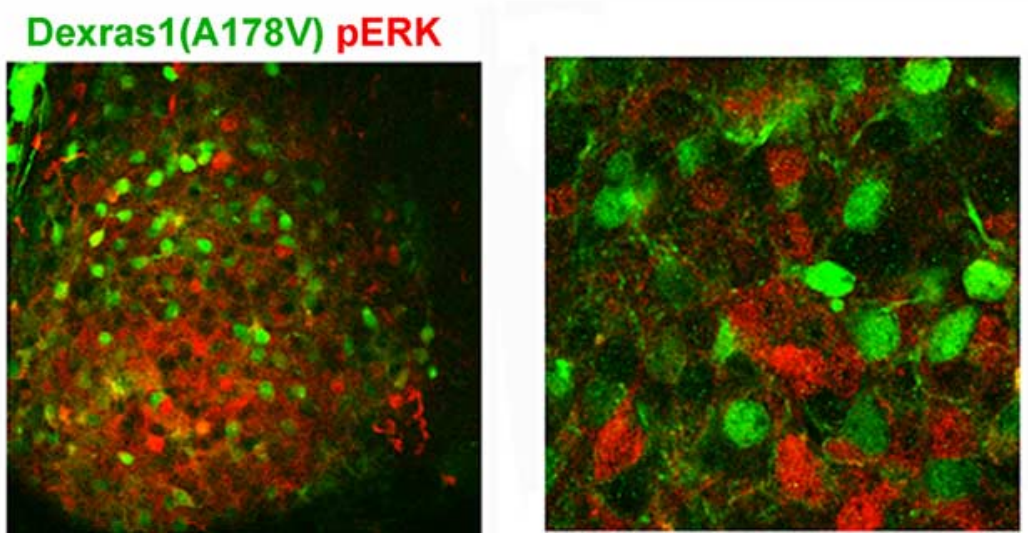

Figure 6. Tetracycline-controlled overexpression of constitutively active Dexras1 in the SCN abrogates MAPK activation in response to nocturnal light. $A$, Experimental schematic to drive SCN-specific expression of the constitutively active Dexras 1 (A178V) mutant using the tetracycline-inducible system. A single transgenic construct containing two genes, constitutively active Dexras 1 harboring the $\mathrm{A} 178 \mathrm{~V}$ point mutation and $\mathrm{GFP}$, in a polycistronic unit under the control of the tetracycline-responsive (tet0) promoter was generated. The Dexras1 (A178V)-IRES-eGFP transgenic mice were bred with the CaMKII $\alpha$-tTA mice. In the absence of the tetracycline analog doxycycline (Dox), double transgenic mice coexpress Dexras1(A178V) and eGFP in a tissuespecific manner. The Dexras1(A178V)-IRES-eGFP founder line \#3901 shown here expresses specifically in the SCN. GFP immunoreactivity was found throughout the $S C N$, marking cells that express the Dexras1(A178V) transgene. $\boldsymbol{B}$, Expression of eGFP in double transgenic mice generated from the breeding of the CaMKIl $\alpha$-tTA strain to Dexras1(A178V)-IRES-eGFP founder lines \#3901 (left) and \#3601 (right). Founder line \#3901 exhibited SCN-specific expression, whereas transgene expression was more broadly expressed in founder line \#3601 and observed in the SCN, cortex, hippocampus, and striatum. C, Light-induced MAPK activation in double transgenic CaMKIl $\alpha$-tTA::Dexras1(A178V)-IRES-eGFP mice. Double transgenic mice received a brief light pulse (15 min; 100 lux) at CT 20, and brain sections were processed 30 min later for expression of p-ERK (red) and GFP (green) using immunofluorescent labeling and confocal microscopy was used to visualize the signals. Cells that express the transgenes do not exhibit p-ERK immunoreactivity after light treatment (left panel). The absence of colocalization of GFP and p-ERK expression is more evident under higher magnification (right panel).

responsiveness, we tested the constitutively active Dexras1 transgenic mice in behavioral assays. Dexras1(A178V)-IRES-eGFP:: CamkII $\alpha$-tTA double transgenic mice (which overexpress constitutively active Dexras1) and the Dexras1(A178V)-IRES-eGFP (which do not) single transgenic controls received a single light pulse (40 lux; $15 \mathrm{~min}$ ) at ZT 8 or ZT 20 under entrained condi-

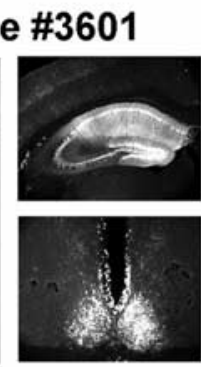

tions (Fig. 8). After 9-10 d of free running in $\mathrm{DD}$, the mice received a second light pulse (40 lux; $15 \mathrm{~min}$ ) at CT 8 or CT 20 (Fig. 8). Daytime light stimulation, whether administered under entrained or free-running conditions, had no phaseshifting effect in the single transgenic mice (Fig. $8 A, E$ ). A small phase advance was observed in double transgenic mice (Fig. $8 B, E)$ in response to a $\mathrm{ZT} 8$ light pulse, but this was not significantly different from that of single transgenic controls. No phase advance was observed in double transgenics after a CT 8 light pulse given under free-running conditions (Fig. $8 B, E)$. These results indicate that photic gating is not compromised in the presence of Dexras1. In contrast, the single transgenics did not phase-shift in response to a ZT 20 light pulse under entrained conditions but exhibited a modest phase advance when light was administered at CT 20 under free-running conditions (Fig. $8 C, E)$. The response of Dexras1(A178V)overexpressing double transgenics to a ZT 20 light pulse was comparable with that of control mice (Fig. 8D,E). However, rather than phase-advancing to light administration under free-running conditions, the double transgenics phase-delayed to CT 20 light (Fig. 8D,E). Interestingly, this phenocopies the behavior of $P A C 1^{-/-}$mice, which show a similar phase delay in response to late-night light stimulation (Hannibal et al., 2001). Together, these data indicate Dexras1 is functioning to suppress PACAP-mediated signaling.

\section{Discussion}

Our results demonstrate the fundamental role of Dexras1 in shaping the phasedependent responsiveness of the mammalian circadian clock to photic entrainment cues. In the absence of Dexras1, the murine circadian system exhibits complex, phase-specific alterations in photic entrainment. Light-induced phase delays are attenuated in the early night, whereas photic phase advances in the late night are potentiated. Surprisingly, daytime gating of photic effects is lost in dexras $1^{-/-}$mice. The capacity to modulate MAPK signaling via discrete, time-of-day-specific signaling events appears to be the principal route by which Dexras1 regulates light sensitivity of the clock (Fig. 9).

Given that the MAPK modulator, Dexras1, is expressed in the SCN and is a target of NMDA receptor/neuronal nitric oxide synthasemediated activation (Fang et al., 2000), combined with evidence showing that photic resetting of the SCN clock requires activation of NMDA receptors, release of NO, and activation of the MAPK cascade (Colwell and Menaker, 1992; Ding et al., 1994; Shibata et 
al., 1994; Mintz et al., 1999; Butcher et al., 2002; Hannibal, 2002), we hypothesized that Dexras1 may regulate aspects of the light entrainment process. As we demonstrated previously, the absence of Dexras 1 was shown to attenuate light-induced phase shifts of behavioral rhythms in the early night as well as NMDA receptor signaling in the SCN (Cheng et al., 2004). This was coincident with a reduction in light-induced MAPK activation in the SCN of dexras1 $1^{-/-}$mice (Cheng et al., 2004).

In light of these results, it was entirely unexpected that the signaling events actuated by late-night light exposure are amplified in the absence of Dexras1, as demonstrated by a greater increase of light-induced p-ERK and c-Fos expression in the SCN of dexras $1^{-/-}$mice compared with wild types. Enhanced MAPK activation in dexras $1^{-/-}$mice is concomitant with a U0126-mediated blockade of phase advances, indicating a causal link between enhanced signaling through the MAPK cascade and a dramatic increase in the sensitivity of the clock to late-night light.

The initial signaling events that mediate the opposite effects of Dexras1 on light-induced phase delays (early night) and phase advances (late night) are clearly distinct. In contrast to the role of Dexras1 as a regulator of NMDA receptormediated early night phase delays, our data suggest that the exaggerated behavioral response of dexras $1^{-/-}$mice to latenight light exposure is mediated by enhanced PACAP/PAC1 signaling in the SCN. Several reports using genetically altered mice indicate that PACAP is a key regulator of late-night phase advances (Hannibal et al., 2001; Kawaguchi et al., 2003); however, there is some discrepancy with respect to the role of PACAP in earlynight phase delays (Hannibal et al., 2001; Kawaguchi et al., 2003; Colwell et al., 2004). Support for a connection between PACAP and Dexras1 came from data showing that pharmacological antagonism of PAC1 receptors blocked photic phase advances in dexras $1^{-1-}$ mice, and that PACAP infusion triggered more robust MAPK pathway activation in dexras1 $1^{-/-}$mice. Moreover, whereas the absence of Dexras1 potentiated light/PACAP effects in vivo, overexpression of Dexras1 attenuated PACAP-mediated downstream signaling in vitro.

Our pharmacological data indicate that Dexras1 attenuates late-night light entrainment by reducing the capacity of PACAP to elicit MAPK activation via PAC1 receptors. However, we cannot exclude the possibility that the effects of PACAP 6-38 are restricted solely to PAC1. In consideration of this, another possible signaling cassette by which Dexras1 mod-

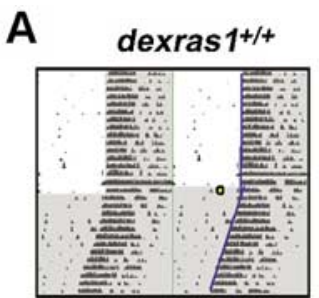

C

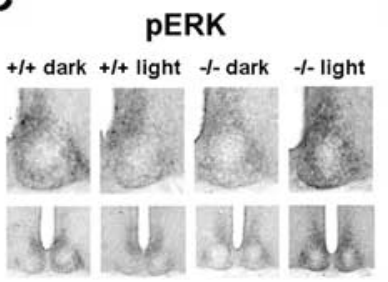

B

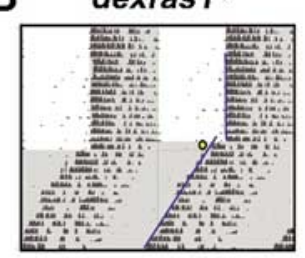

D

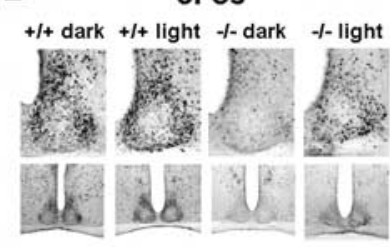

E

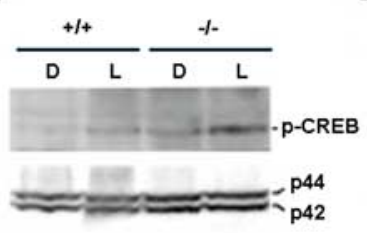

$\mathbf{F}$

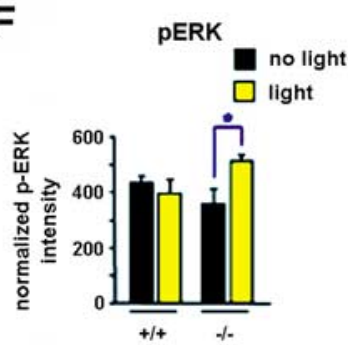

G

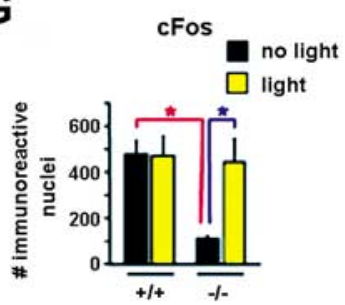

H

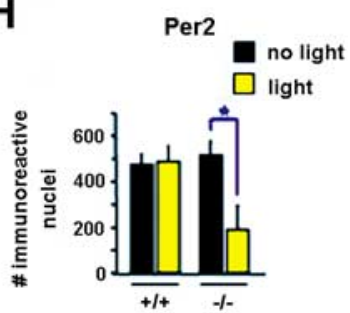

$\mathrm{J}$ dexras $1 \% \quad \mathrm{~K}$ dexras $1 \%$
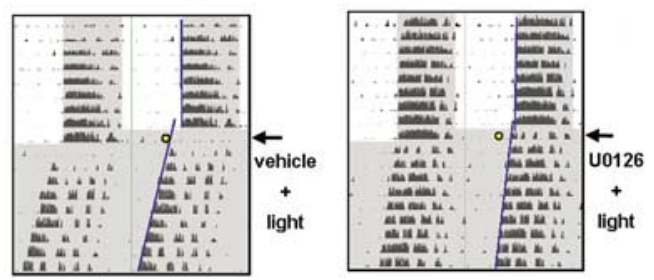

Figure 7. The absence of Dexras1 reveals a mid-day photic response in the SCN. $\boldsymbol{A}, \boldsymbol{B}$, Representative actograms of wheelrunning activity of dexras $1^{+/+}(\boldsymbol{A})$ and dexras $1^{-/-}(\boldsymbol{B})$ mice. Mice were exposed to a single 40 lux light pulse for $15 \mathrm{~min}$ at ZT 8 (yellow circle), exactly as described in Figure 1. Activity onsets are indicated by blue lines. $\mathbf{C} \boldsymbol{E}$, Immunohistochemical analysis of p-ERK $(\boldsymbol{C}), \mathrm{c}-$ Fos $(\boldsymbol{D})$, and Per2 (E) expression in response to a single $5 \mathrm{~min}$ (for p-ERK) or $15 \mathrm{~min}$ (for c-Fos and Per2) light pulse at CT 6. Wild-type $(+/+)$ and knock-out (-/-) mice were killed immediately (for $\mathrm{p}$-ERK), $2 \mathrm{~h}$ (for c-Fos), or $6 \mathrm{~h}$ (for Per2) after the light treatment. Dark control animals were not exposed to light but were killed at the same circadian times. Light exposure in the subjective daytime had no effect on p-ERK, c-Fos, and Per2 levels in the SCN of wild-type mice. Baseline levels of c-Fos were reduced in dexras $1^{-1-}$ mice relative to wild-type controls. A single light pulse in the mid-subjective day increased p-ERK and c-Fos immunoreactivity in the SCN of dexras $1^{-/-}$mice. Per2 immunoreactivity was decreased in dexras $1^{-/-} \mathrm{SCN}$ after light treatment. $\boldsymbol{F}-\boldsymbol{H}$, Quantitation of p-ERK $(\boldsymbol{F}), \boldsymbol{c}-\mathrm{Fos}(\boldsymbol{G})$, and Per2 $(\boldsymbol{H})$ expression in the SCN. Data are presented as mean \pm SEM densitometric intensity (for $p$-ERK) or mean \pm SEM number of immunoreactive nuclei per SCN section (for c-Fos and Per2). $n=$ 4- 6 per group. ${ }^{*} p<0.05$ (two-tailed Student's $t$ test). I, Western blot analysis of light-induced $p$-CREB expression in the SCN. Wild-type $(+/+)$ and dexras $1^{-/-}(-/-)$mice received a single light pulse (15 min, 40 lux) at $\mathrm{CT} 6$, and the SCN was dissected 30 min after the start of the light exposure. Pooled SCN extracts were probed for the expression of p-CREB. Expression of total ERK1/2 (p42, p44) was used as the loading control. L denotes light-treated mice, whereas D denotes dark controls. J, $\boldsymbol{K}$, U0126 inhibits ZT 8 light-induced phase advances in dexras $1^{-/}$mice. Representative actograms of wheel-running activity of dexras $1^{-1-}$ mice are shown. Mice were entrained to a $12 \mathrm{~h} \mathrm{LD}$ schedule (400 lux). On the day of the experiment, lights remained off at ZT 0 . Thirty minutes before a 15 min light pulse of 40 lux at ZT 8 (yellow circle), mice were infused with vehicle (DMSO) (J) or U0126 (10 mm; $3 \mu \mathrm{l})(\boldsymbol{K})$ via a guide cannula placed in the third ventricle. Subsequent to the light pulse, animals were maintained in DD for at least $7 \mathrm{~d}$. Activity onsets are indicated by blue lines.

ulates MAPK activation within the SCN is the following: glutamate-vasoactive intestinal peptide (VIP)-VPAC2/PAC1Dexras1-MAPK. VIP, which is expressed by retinorecipient SCN neurons, has been shown to phase-shift SCN firing rhythms in vitro in a manner similar to light or glutamate (Reed et al., 2001). 
A

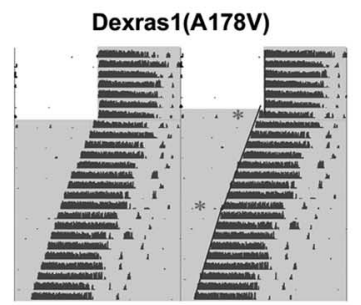

C

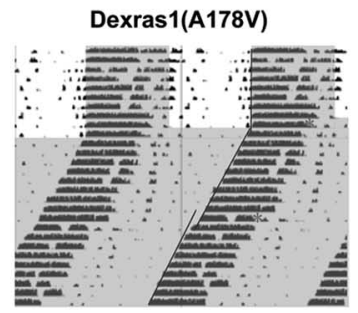

B

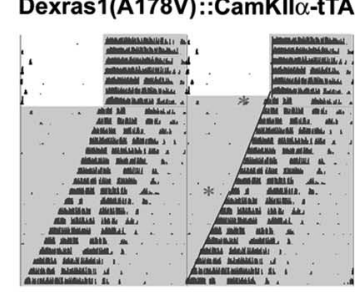

D Dexras1(A178V)::CamKIll $\alpha-t T A$

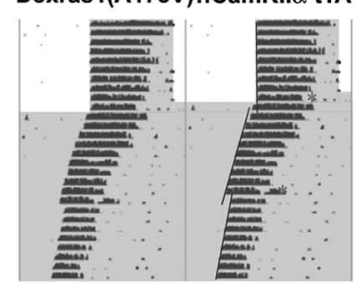

E

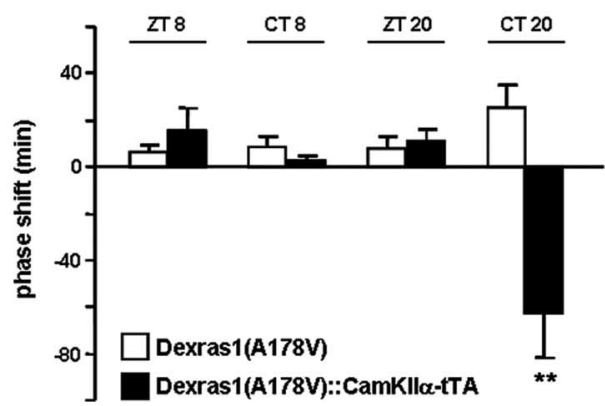

Figure 8. Mice that overexpress constitutive active Dexras1 specifically in the SCN phasedelay in response to late-night light exposure. $\boldsymbol{A}-\boldsymbol{D}$, Representative actograms of wheelrunning activity of Dexras1(A178V) single transgenic $(\boldsymbol{A}, \boldsymbol{C})$ and Dexras1(A178V)-IRES-eGFP: CaMKIl $\alpha$-tTA double transgenic $(\boldsymbol{B}, \boldsymbol{D})$ mice. Mice were exposed to a single 40 lux light pulse (red asterisk) for 15 min at ZT $8(\boldsymbol{A}, \boldsymbol{B})$ or ZT $20(\boldsymbol{C}, \boldsymbol{D})$, exactly as described in Figure 1. Mice received a second light pulse ( 40 lux; $15 \mathrm{~min}$ ) at CT $8(\boldsymbol{A}, \boldsymbol{B})$ or $\mathrm{CT} 20(\boldsymbol{C}, \boldsymbol{D})$ after $9-10 \mathrm{~d}$ in DD. Activity onsets are indicated by blue lines. $E$, Quantitation of light-induced phase shifts. Values are presented as mean \pm SEM phase shift (in minutes). $n=6-8$ per group. ${ }^{* *} p<0.01$ versus same-treated Dexras1(A178V) single transgenic mice (two-tailed Student's $t$ test).

Moreover, VIP resetting effects are mimicked by a VPAC2 agonist and are abrogated by U0126 (Reed et al., 2001; MeyerSpasche and Piggins, 2004). With regard to VPAC2 signaling, the receptor shows equal affinity for PACAP and VIP (Harmar et al., 1998); therefore, some cellular effects of PACAP within the murine SCN may be mediated in part by VPAC2 receptors (Reed et al., 2002).

To address the actions of Dexras 1 in the late night, we focused on the role of PACAP/PAC1-G-protein-mediated signaling. In vitro, Dexras1-dependent attenuation of PACAP-induced MAPK activity was attributed to an inhibitory effect on both $\mathrm{G} \beta \gamma$ and $\mathrm{G}_{\mathrm{s}} \alpha$ signaling. MAPKs are downstream effectors of $\mathrm{G} \beta \gamma$ signaling and, as with other targets of $\mathrm{G} \beta \gamma$-mediated signaling, have been shown to be negatively modulated by Dexras1 (Takesono et al., 2002). At the same time, enhanced $\mathrm{G}_{\mathrm{i}} \alpha$ signaling in Dexras1expressing neurons likely accounts for the suppression of $\mathrm{G}_{\mathrm{s}} \alpha$ mediated MAPK activation. Although Dexras1 has been shown to inhibit GPCR-dependent activation of heterotrimeric G-proteins, the ability of Dexras1 to independently cause GTP/ GDP exchange on monomeric $\mathrm{G}_{\mathrm{i}} \alpha$ subunits has been demonstrated in biochemical studies (Cismowski et al., 2000). Pertussis toxin, which acts only on the inactive, heterotrimeric form of $\mathrm{G}_{\mathrm{i} / \mathrm{o}}$-proteins, is without effect on PACAP-dependent MAPK ac- tivation in neurons that overexpress Dexras1. This supports our hypothesis that Dexras1 is an intracellular, receptor-independent promoter of the active, monomeric form of $\mathrm{G}_{\mathrm{i}} \alpha$, which provides an inhibitory tone to $\mathrm{G}_{\mathrm{s}} \alpha$ signaling.

In addition, we provide multiple lines of evidence that Dexras1 inhibits AC signaling (Graham et al., 2004; Nguyen and Watts, 2005). Forskolin-induced activation of CRE-dependent transcription is inhibited in Dexras1-expressing neurons in vitro. Moreover, basal and light-inducible levels of cAMP as well as active, phospho-CREB are greater in the SCN of dexras $1^{-/-}$mice versus wild types. These inhibitory effects of Dexras1 were realized at the level of the MAPK pathway: forskolin-induced MAPK activity was inhibited by Dexras1. The augmentation of PACAP/ PAC1-mediated signaling in dexras1 ${ }^{-1-}$ mice may in part be attributed to enhanced $\mathrm{G}_{\mathrm{s}} / \mathrm{AC}$ signaling, whereas the accumulation of cAMP in the SCN of dexras $1^{-1-}$ mice may play a role in the late-night photic phase advances.

Most surprising was our finding that genetic ablation of Dexras1 revealed a response to daytime light. A lack of responsiveness to daytime light is a fundamental feature of all biological clocks. In light of a possible role of VPAC2 signaling in dexras $1^{-/-}$mice, it is interesting to note that photic gating is also compromised in $V P A C 2^{-1-}$ mice, which showed light-induced expression of p-ERK and c-Fos in both the subjective day and night (Hughes et al., 2004). Generally speaking, there are two possible explanations for how daytime light couples to the clock in dexras $1^{-1-}$ mice. First, ablation of Dexras1 might reveal a capacity of photic stimulation to elicit a behavioral arousal-like entrainment cue, which in turn would result in a nonphotic phase shift. Second, ablation of Dexras1 might reveal a novel photic entrainment mechanism that is distinct from an arousal-like entrainment cue.

The possibility that the loss of Dexras1 reveals a photically activated arousal entrainment cue is supported by our data showing that a midday light pulse in dexras $1^{-/-}$mice suppressed Per2 protein expression in the SCN in a similar manner as exposure to a nonphotic stimulus (Maywood et al., 1999). In contrast, there are distinct differences between photic and nonphotic phase advances in the subjective day. For example, nonphotic stimulation leaves c-Fos levels in the SCN unchanged (Mead et al., 1992) or decreased (Mikkelsen et al., 1998), but we observed daytime photic induction of p-ERK and c-Fos in the SCN of dexras $1^{-1-}$ mice.

If a direct photic entrainment mechanism underlies daytime clock entrainment in dexras $1^{-1-}$ mice, it would appear that the signaling events underlying daytime and nighttime lightentrainment are distinct. Although U0126 blocked the phaseshifting effect of light at ZT 8 and ZT 20, only a light pulse administered at ZT 20 evoked the expected p-ERK and c-Fos expression in the SCN core. Daytime light exposure induced the expression of p-ERK and c-Fos in the SCN shell without a similar response in the SCN core.

The mechanistic basis for light-induced MAPK activation exclusively in the SCN shell is unclear. Although the SCN core has been considered as the retinorecipient region, a recent study indicated that projections of melanopsin-expressing retinal ganglion cells were not restricted to this region but filled the entire murine SCN, including the core and shell subcompartments (Hattar et al., 2006). Hence, it is possible that light may trigger MAPK activation in the SCN shell without a requirement for concurrent activation in the SCN core. Alternatively, the SCN shell is densely innervated by galanin-positive afferents from the anterior hypothalamus/preoptic area (Abrahamson and Moore, 2001). The intergeniculate leaflet (IGL), which mediates both 
photic and nonphotic effects, receives afferent inputs from the RHT and projects to a number of brain regions, including the SCN and the anterior hypothalamus (Morin and Blanchard, 1999). As such, the anterior hypothalamus may serve as a secondary route by which photic (and nonphotic) cues arising from the IGL reaches the SCN shell. Regardless of the mechanism, the results indicate that genetic ablation of Dexras1 eliminates a daytime gate that otherwise limits access of photic information to the SCN shell but does not compromise gating of the SCN core. Additional work will be required to determine both the synaptic circuitry and precise cellular signaling events that underlie light-induced phase advancing in dexras $1^{-/-}$mice during the subjective day.

\section{References}

Abrahamson EE, Moore RY (2001) Suprachiasmatic nucleus in the mouse: retinal innervation, intrinsic organization and efferent projections. Brain Res 916:172-191.

Barrie AP, Clohessy AM, Buensuceso CS, Rogers MV, Allen JM (1997) Pituitary adenylyl cyclase-activating peptide stimulates extracellular signal-regulated kinase 1 or 2 (ERK1/2) activity in a Ras-independent, mitogen-activated protein kinase/ERK kinase 1 or 2-dependent manner in PC12 cells. J Biol Chem 272:19666-19671.

Bergstrom AL, Hannibal J, Hindersson P, Fahrenkrug J (2003) Light-induced phase shift in the Syrian hamster (Mesocricetus auratus) is attenuated by the PACAP receptor antagonist PACAP6-38 or PACAP immunoneutralization. Eur J Neurosci 18:2552-2562.

Bobrzynska KJ, Mrosovsky N (1998) Phase shifting by novelty-induced running: activity doseresponse curves at different circadian times. J Comp Physiol 182:251-258.

Butcher GQ, Dziema H, Collamore M, Burgoon PW, Obrietan K (2002) The p42/p44 mitogen-activated protein kinase pathway couples photic input to circadian clock entrainment. J Biol Chem 277:29519-29525.

Butcher GQ, Lee B, Cheng HY, Obrietan K (2005) Light stimulates MSK1 activation in the suprachiasmatic nucleus via a PACAP-ERK/MAP kinase-dependent mechanism. J Neurosci 25:5305-5313.

Chen D, Buchanan GF, Ding JM, Hannibal J, Gillette MU (1999) Pituitary adenylyl cyclaseactivating peptide: a pivotal modulator of glutamatergic regulation of the suprachiasmatic circadian clock. Proc Natl Acad Sci USA 96:13468-13473.

Cheng HYM, Obrietan K, Cain SW, Lee BY, Agostino PV, Joza NA, Harrington ME, Ralph MR, Penninger JM (2004) Dexrasl potentiates photic and suppresses nonphotic responses of the circadian clock. Neuron 43:715-728.

Chung H, Brautigan DL (1999) Protein phosphatase 2A suppresses MAP kinase signalling and ectopic protein expression. Cell Signal 11:575-580.

Cismowski MJ, Takesono A, Ma C, Lizano JS, Xie X, Fuernkranz H, Lanier SM, Duzic E (1999) Genetic screens in yeast to identify mammalian nonreceptor modulators of G-protein signaling. Nat Biotechnol 17:878-883.

Cismowski MJ, Ma C, Ribas C, Xie X, Spruyt M, Lizano JS, Lanier SM, Duzic
E (2000) Activation of heterotrimeric G-protein signaling by a rasrelated protein. Implications for signal integration. J Biol Chem 275:23421-23424.

Colwell CS, Menaker M (1992) NMDA as well as non-NMDA receptor antagonists can prevent the phase-shifting effects of light on the circadian system of the golden hamster. J Biol Rhythms 7:125-136.

Colwell CS, Michel S, Itri J, Rodriguez W, Tam J, Lelievre V, Hu Z, Waschk JA (2004) Selective deficits in the circadian light response in mice lacking PACAP. Am J Physiol Regul Integr Comp Physiol 287:R1194-R1201.

Coogan AN, Piggins HD (2003) Circadian and photic regulation of phos- 
phorylation of ERK1/2 and Elk-1 in the suprachiasmatic nuclei of the Syrian hamster. J Neurosci 23:3085-3093.

Daan S, Pittendrigh CS (1976) A functional analysis of circadian pacemakers in nocturnal rodents. II. The variability of phase response curves. J Comp Physiol 106:253-266.

Decoursey PJ (1964) Function of a light response rhythm in hamsters. J Cell Physiol 63:189-196.

Ding JM, Chen D, Weber ET, Faiman LE, Rea MA, Gillette MU (1994) Resetting the biological clock: mediation of nocturnal circadian shifts by glutamate and NO. Science 266:1713-1717.

Dunlap JC (1999) Molecular bases for circadian clocks. Cell 96:271-290.

Dziema H, Obrietan K (2002) PACAP potentiates L-type calcium channel conductance in suprachiasmatic nucleus neurons by activating the MAPK pathway. J Neurophysiol 88:1374-1386.

Dziema H, Oatis B, Butcher GQ, Yates R, Hoyt KR, Obrietan K (2003) The ERK/MAP kinase pathway couples light to immediate-early gene expression in the suprachiasmatic nucleus. Eur J Neurosci 17:1617-1627.

Fang M, Jaffrey SR, Sawa A, Ye K, Luo X, Snyder SH (2000) Dexras1: a G protein specifically coupled to neuronal nitric oxide synthase via CAPON. Neuron 28:183-193.

Graham TE, Key TA, Kilpatrick K, Dorin RI (2001) Dexras1/AGS-1, a steroid hormone-induced guanosine triphosphate-binding protein, inhibits $3^{\prime}, 5^{\prime}$-cyclic adenosine monophosphate-stimulated secretion in AtT-20 corticotroph cells. Endocrinology 142:2631-2640.

Graham TE, Prossnitz ER, Dorin RI (2002) Dexras1/AGS-1 inhibits signal transduction from the Gi-coupled formyl peptide receptor to Erk-1/2 MAP kinases. J Biol Chem 277:10876-10882.

Graham TE, Qiao Z, Dorin RI (2004) Dexras1 inhibits adenylyl cyclase. Biochem Biophys Res Commun 316:307-312.

Hannibal J (2002) Neurotransmitters of the retino-hypothalamic tract. Cell Tissue Res 309:73-88.

Hannibal J, Jamen F, Nielsen HS, Journot L, Brabet P, Fahrenkrug J (2001) Dissociation between light-induced phase shift of the circadian rhythm and clock gene expression in mice lacking the pituitary adenylate cyclase activating polypeptide type 1 receptor. J Neurosci 21:4883-4890.

Harmar AJ, Arimura A, Gozes I, Journot L, Laburthe M, Pisegna JR, Rawlings SR, Robberecht P, Said SI, Sreedharan SP, Wank SA, Waschek JA (1998) International union of pharmacology. XVIII. Nomenclature of receptors for vasoactive intestinal peptide and pituitary adenylate cyclase-activating polypeptide. Pharmacol Rev 50:265-270.

Hattar S, Kumar M, Park A, Tong P, Tung J, Yau KW, Berson DM (2006) Central projections of melanopsin-expressing retinal ganglion cells in the mouse. J Comp Neurol 497:326-349.

Hughes AT, Fahey B, Cutler DJ, Coogan AN, Piggins HD (2004) Aberrant gating of photic input to the suprachiasmatic circadian pacemaker of mice lacking the VPAC2 receptor. J Neurosci 24:3522-3526.

Kawaguchi C, Tanaka K, Isojima Y, Shintani N, Hashimoto H, Baba A, Nagai K (2003) Changes in light-induced phase shift of circadian rhythm in mice lacking PACAP. Biochem Biophys Res Commun 310:169-175.

Lee B, Butcher GQ, Hoyt KR, Impey S, Obrietan K (2005) Activitydependent neuroprotection and cAMP response element-binding protein (CREB): kinase coupling, stimulus intensity, and temporal regulation of CREB phosphorylation at serine 133. J Neurosci 25:1137-1148.

Mayford M, Bach ME, Huang YY, Wang L, Hawkins RD, Kandel ER (1996) Control of memory formation through regulated expression of a CaMKII transgene. Science 274:1678-1683.

Maywood ES, Mrosovsky N, Field MD, Hastings MH (1999) Rapid downregulation of mammalian period genes during behavioral resetting of the circadian clock. Proc Natl Acad Sci USA 96:15211-15216.

Mead S, Ebling FJ, Maywood ES, Humby T, Herbert J, Hastings MH (1992) A nonphotic stimulus causes instantaneous phase advances of the lightentrainable circadian oscillator of the Syrian hamster but does not induce the expression of c-fos in the suprachiasmatic nuclei. J Neurosci 12: $2516-2522$

Meyer-Spasche A, Piggins HD (2004) Vasoactive intestinal polypeptide phase-advances the rat suprachiasmatic nuclei circadian pacemaker in vitro via protein kinase $\mathrm{A}$ and mitogen-activated protein kinase. Neurosci Lett 358:91-94.

Mikkelsen JD, Vrang N, Mrosovsky N (1998) Expression of Fos in the circadian system following nonphotic stimulation. Brain Res Bull 47: 367-376.

Mintz EM, Marvel CL, Gillespie CF, Price KM, Albers HE (1999) Activation of NMDA receptors in the suprachiasmatic nucleus produces light-like phase shifts of the circadian clock in vivo. J Neurosci 19:5124-5130.

Morin LP, Blanchard JH (1999) Forebrain connections of the hamster intergeniculate leaflet: comparison with those of ventral lateral geniculate nucleus and retina. Vis Neurosci 16:1037-1054.

Nguyen CH, Watts VJ (2005) Dexras1 blocks receptor-mediated heterologous sensitization of adenylyl cyclase 1 . Biochem Biophys Res Commun 332:913-920.

Norum JH, Hart K, Levy FO (2003) Ras-dependent ERK activation by the human G, (s)-coupled serotonin receptors 5-HT4 (b) and 5-HT7 (a). J Biol Chem 278:3098-3104.

Obrietan K, Impey S, Storm DR (1998) Light and circadian rhythmicity regulate MAP kinase activation in the suprachiasmatic nuclei. Nat Neurosci 1:693-700.

Obrietan K, Impey S, Smith D, Athos J, Storm DR (1999) Circadian regulation of cAMP response element-mediated gene expression in the suprachiasmatic nuclei. J Biol Chem 274:17748-17756.

Panda S, Antoch MP, Miller BH, Su AI, Schook AB, Straume M, Schultz PG, Kay SA, Takahashi JS, Hogenesch JB (2002) Coordinated transcription of key pathways in the mouse by the circadian clock. Cell 109:307-320.

Pittendrigh CS, Daan S (1976) A functional analysis of circadian pacemakers in nocturnal rodents. IV. Entrainment: pacemaker as clock. J Comp Physiol 106:291-331.

Ralph MR, Foster RG, Davis FC, Menaker M (1990) Transplanted suprachiasmatic nucleus determines circadian period. Science 247:975-978.

Reed HE, Meyer-Spasche A, Cutler DJ, Coen CW, Piggins HD (2001) Vasoactive intestinal polypeptide (VIP) phase-shifts the rat suprachiasmatic nucleus clock in vitro. Eur J Neurosci 13:839-843.

Reed HE, Cutler DJ, Brown TM, Brown J, Coen CW, Piggins HD (2002) Effects of vasoactive intestinal polypeptide on neurones of the rat suprachiasmatic nuclei in vitro. J Neuroendocrinol 14:639-646.

Robberecht P, Gourlet P, De Neef P, Woussen-Colle MC, Vandermeers-Piret MC, Vandermees A, Christophe J (1992) Structural requirements for the occupancy of pituitary adenylate-cyclase-activating-peptide (PACAP) receptors and adenylate cyclase activation in human neuroblastoma NB-OK-1 cell membranes. Discovery of PACAP(6-38) as a potent antagonist. Eur J Biochem 207:239-246.

Rusak B, McNaughton L, Robertson HA, Hunt SP (1992) Circadian variation in photic regulation of immediate-early gene mRNAs in rat suprachiasmatic nucleus cells. Brain Res Mol Brain Res 14:124-130.

Shibata S, Watanabe A, Hamada T, Ono M, Watanabe S (1994) N-methyl$\mathrm{D}$-aspartate induces phase shifts in circadian rhythm of neuronal activity of rat SCN in vitro. Am J Physiol 267:R360-R364.

Spengler D, Waeber C, Pantaloni C, Holsboer F, Bockaert J, Seeburg PH, Journot L (1993) Differential signal transduction by five splice variants of the PACAP receptor. Nature 365:170-175.

Takahashi H, Umeda N, Tsutsumi Y, Fukumura R, Ohkaze H, Sujino M, van der Horst G, Yasui A, Inouye ST, Fujimori A, Ohhata T, Araki R, Abe M (2003) Mouse dexamethasone-induced RAS protein 1 gene is expressed in a circadian rhythmic manner in the suprachiasmatic nucleus. Brain Res Mol Brain Res 110:1-6.

Takesono A, Nowak MW, Cismowski M, Duzic E, Lanier SM (2002) Activator of G-protein signaling 1 blocks GIRK channel activation by a G-protein-coupled receptor: apparent disruption of receptor signaling complexes. J Biol Chem 277:13827-13830.

Tsai SC, Adamik R, Kanaho Y, Hewlett EL, Moss J (1984) Effects of guanyl nucleotides and rhodopsin on ADP-ribosylation of the inhibitory GTPbinding component of adenylate cyclase by pertussis toxin. J Biol Chem 259:15320-15323.

Ueda HR, Chen W, Adachi A, Wakamatsu H, Hayashi S, Takasugi T, Nagano M, Nakahama K, Suzuki Y, Sugano S, Iino M, Shigeyoshi Y, Hashimoto S (2002) A transcription factor response element for gene expression during circadian night. Nature 418:534-539.

Yan L, Silver R (2002) Differential induction and localization of mPerl and $\mathrm{mPer} 2$ during advancing and delaying phase shifts. Eur J Neurosci 16: $1531-1540$. 